\title{
Sequence and structural elements critical for U8 snRNP function in Xenopus oocytes are evolutionarily conserved
}

\author{
Brenda A. Peculis and Joan A. Steitz \\ Department of Molecular Biophysics and Biochemistry, Howard Hughes Medical Institute, Yale University Medical School, \\ New Haven, CT 06536 USA
}

\begin{abstract}
We have generated mutants in Xenopus U8 RNA, a nucleolar snRNA required for the maturation of 5.8S and 28S rRNAs, to identify sequences and structural domains essential for RNA stability, particle assembly, and function of the U8 RNP. Activity of the mutants was assayed by microinjection of in vitro-synthesized U8 RNAs into the cytoplasm of Xenopus oocytes. Most of the mutant RNAs were stable, bound fibrillarin, a protein common to several of the nucleolar-specific snRNPs, and became hypermethylated. Although hypermethylation of the $5^{\prime}$ cap of U8 RNA and fibrillarin binding can occur in either the cytoplasmic or nuclear compartment of Xenopus oocytes, neither is required for nuclear import. We find that the trimethylguanosine cap, although present on the endogenous U8 RNA, is not essential for stability, particle assembly, or functioning of U8 in the coordinate processing of pre-rRNA at sites $3^{\prime}$ of $28 S$ and $5^{\prime}$ of 5.8S RNA. Several conserved single- and double-stranded sequences within the $5^{\prime}$ domain of U8 RNA are essential for function.
\end{abstract}

[Key Words: nucleolar snRNP function; Xenopus oocyte; RNA stability; particle assembly; rRNA processing; ribosome biogenesis]

Received May 23, 1994; revised version accepted August 3, 1994.

The nucleolus is the site of rRNA transcription and ribosome biogenesis. Pre-rRNA is synthesized as a long precursor that binds ribosomal proteins and undergoes processing at several sites to yield mature $18 \mathrm{~S}, 5.8 \mathrm{~S}$, and 28S rRNAs, which exit the nucleus in the form of ribosomal subunits. Recently, several nucleolar small nuclear ribonucleoprotein particles (snRNPs) have been shown to play critical roles in the processing of prerRNA. In yeast, genetic depletion of U3 and U14 snRNPs resulted in the absence of mature 18S rRNA ( $\mathrm{Li}$ et al. 1990; Hughes and Ares 1991). Similar results were obtained when U3 RNA was depleted from Xenopus oocytes by microinjecting U3 antisense deoxyoligonucleotides (Savino and Gerbi 1990); in vitro, the U3 snRNP has been shown to act in early cleavage near the $5^{\prime}$ end of the rRNA transcript (Kass et al. 1990). Genetic depletion of snR30, an essential snRNA in yeast, also affects 18S maturation (Morrissey and Tollervey 1993). Previously, we demonstrated that U8 snRNA is involved in the processing of $5.8 \mathrm{~S}$ and $28 \mathrm{~S}$ rRNAs (Peculis and Steitz 1993). Depletion of the endogenous pool of U8 RNA from Xenopus oocytes caused an inhibition of prerRNA processing at specific sites leading to an absence of mature $28 \mathrm{~S}$ rRNA and of a $12 \mathrm{~S}$ precursor to $5.8 \mathrm{~S}$ rRNA, resulting in an accumulation of abnormal precursors of
$28 S$ rRNA. Subsequent microinjection of in vitro-synthesized U8 RNAs into the cytoplasmic compartment of U8-depleted oocytes could restore, or "rescue," prerRNA processing (Peculis and Steitz 1993).

Although snRNAs are transcribed and function within the nucleus, several snRNAs are known to undergo bidirectional transport across the nuclear envelope. The abundant splicing RNAs (U1, U2, U4, and U5) are transcribed by RNA polymerase II in the nucleus (Dahlberg and Lund 1988) and exported to the cytoplasm where they assemble with the common Sm proteins and the 7-methyl G cap is hypermethylated to 2,2,7-trimethylguanosine (TMG) (Mattai 1986, 1988; Hamm et al. 1990a). After particle assembly the snRNPs accumulate in the nucleus where they function in the splicing of pre-mRNAs (DeRobertis et al. 1982; Fischer et al. 1991; for review, see Moore et al. 1993). The requirements for nuclear import vary. $U 1$ and $U 2$ snRNAs require binding of the Sm proteins for hypermethylation to occur (Mattaj 1986, 1988; Hamm et al. 1990a). In Xenopus oocytes, a bipartite signal of Sm proteins plus TMG cap is essential for nuclear import (Fischer and Lührmann 1990; Hamm et al. 1990a). In somatic cells the requirements for import of $\mathrm{U} 1$ and $\mathrm{U} 2$ are less stringent and resemble more closely those of U4 and U5 snRNAs, which bind the Sm 
proteins in the cytoplasm but do not require hypermemethylation for nuclear import (Fischer et al. 1991, 1993; Marshallsay and Lührmann 1994).

Like the splicing RNPs, some of the nucleolar small nuclear RNAs (snRNAs) associate with a common protein, fibrillarin, and are synthesized by RNA polymerase II. The genes for these RNAs (U3, U8, and U13) have their own promoters, and their transcripts become hypermethylated (Reddy et al. 1979, 1985; Tyc and Steitz 1989; Savino and Gerbi 1990; Peculis and Steitz 1993). Other fibrillarin-associated nucleolar snRNAs (U14, U15, U16, U18, and U21) are intron-encoded (Liu and Maxwell 1990; Fragapane et al. 1993; Prislei et al. 1993; Tycowski et al. 1993; K. Tycowski, pers. comm.). Fibrillarin is a $34-\mathrm{kD}$ protein that has been conserved through evolution from yeast to mammals (Lischwe et al. 1985; Schimmang et al. 1989; Jansen et al. 1991), and a possible homolog has been identified recently in the Archaea (Amiri 1994). Previous studies have demonstrated that fibrillarin binding requires two conserved sequences in the RNA, boxes C and D (Jarmolowski et al. 1990; Baserga et al. 1991). Studies with in vitro-synthesized U3 RNA showed that fibrillarin binding could occur in the cytoplasmic compartment of Xenopus oocytes (Baserga et al. 1992). However, oocytes do not stockpile fibrillarin in the cytoplasm; most of the fibrillarin is located in the nucleus (Caizergues-Ferrer et al. 1991). It is not known whether fibrillarin binding is essential for the localization of snRNAs to the nucleolus; there are several nucleolar snRNAs that do not bind fibrillarin (U17, U19, E2, and E3) (Kiss and Filipowicz 1993; Ruff et al. 1993; Cecconi et al. 1994). Likewise, fibrillarin is not required to retain the nucleolar snRNAs within the nucleolus; genetic depletion of NOP1, the yeast homolog of fibrillarin, does not alter the nucleolar localization of U3 RNA (Tollervey et al. 1991).

Mutations in snRNP RNAs can affect function in several ways. They may disrupt sequences or structures in the RNA essential for substrate recognition, for protein binding, or for interaction with other components of the processing apparatus. Alternatively, mutations may interfere with the cellular localization of the snRNP particles, precluding access to the substrate. We have generated mutants to examine the particle assembly, cellular localization, and function of U8 RNA. We have focused on evolutionarily conserved nucleotides or secondary structures and have utilized injection of in vitrosynthesized U8 RNA into the cytoplasm of Xenopus oocytes. Although the endogenous U8 RNA is hypermethylated, to our surprise, we find that the TMG cap is not critical for stability, assembly, or function of the U8 RNP. We identify certain evolutionarily conserved sequences in single- and double-stranded regions that are important for function.

\section{Results}

The hypermethylated cap is not essential for $U 8$ function

We first examined whether the TMG cap is essential for function of the Xenopus U8 RNP. The endogenous pool of U8 RNA was depleted in oocytes by microinjection of a deoxyoligonucleotide complementary to nucleotides 39-48 in U8 RNA (Peculis and Steitz 1993). After $4 \mathrm{hr}$, sufficient time for this deoxyoligonucleotide to be degraded in vivo (data not shown), the oocytes were microinjected with U8 RNA synthesized in vitro. RNAs transcribed from a U8 cDNA template were primed with either a GpppG (G-cap) or ApppG (A-cap) dinucleotide and contained three extra guanosine residues at the $5^{\prime}$ end (to enhance T7 transcription). The 3' end of the transcribed RNA was identical to the endogenous U8 RNA (Peculis and Steitz 1993). A subsequent 4-hr incubation allowed particle assembly and nuclear accumulation, after which oocytes were microinjected with $\left[{ }^{32} \mathrm{P}\right]$ UTP to label nascent RNAs.

Figure 1 (lanes 1) shows the in vivo-labeled RNAs isolated from the cytoplasmic (A) or nuclear (B) compartments of untreated oocytes. The normal pre-rRNA processing pattern is seen. Mature $18 \mathrm{~S}$ and $28 \mathrm{~S}$ rRNAs accumulate in the cytoplasm (Fig. 1A, lane 1), whereas prerRNAs are observed in the nucleus (Fig. 1B). In Xenopus, there are two alternative processing pathways that can coexist in a single oocyte (Fig. 2B) (Savino and Gerbi 1990; Peculis and Steitz 1993). The oocytes shown in Figure 1 utilize both pathways, although pathway A is predominant; 20S rRNA accumulates at the expense of

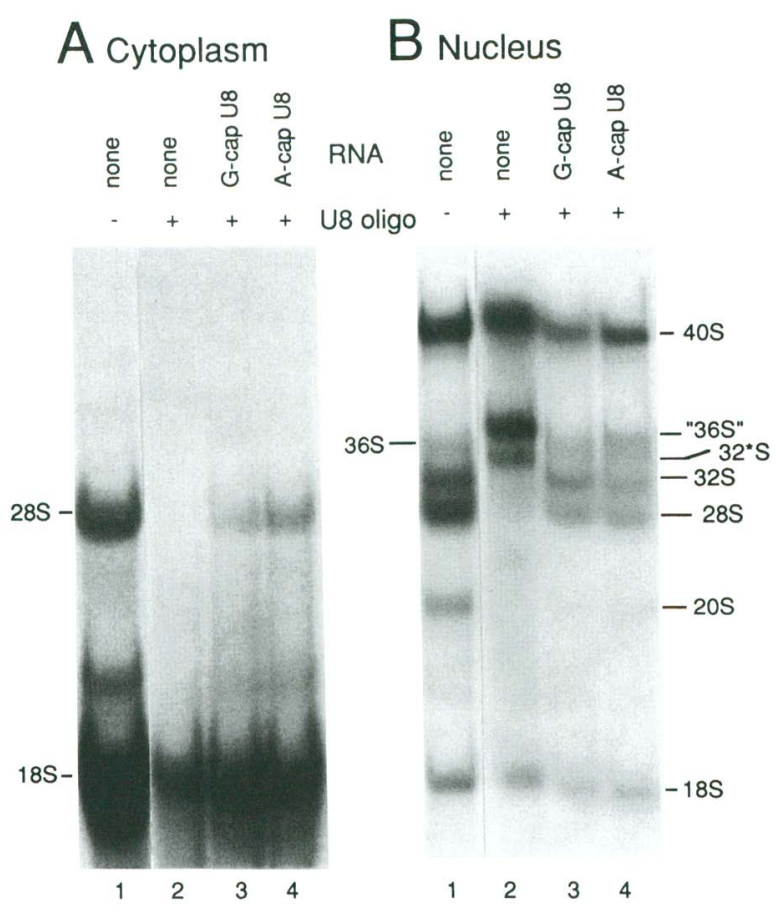

Figure 1. Rescue of rRNA processing with in vitro-synthesized U8 RNA. In vivo-labeled RNAs isolated from the cytoplasmic $(A)$ or nuclear $(B)$ compartments of oocytes. (Lanes 1$)$ RNA from untreated oocytes; (lanes 2), RNA from U8-depleted oocytes. RNA from U8-depleted oocytes subsequently injected with G-cap U8 RNA is shown in lanes 3, or A-cap U8 RNA in lanes 4 . 
A
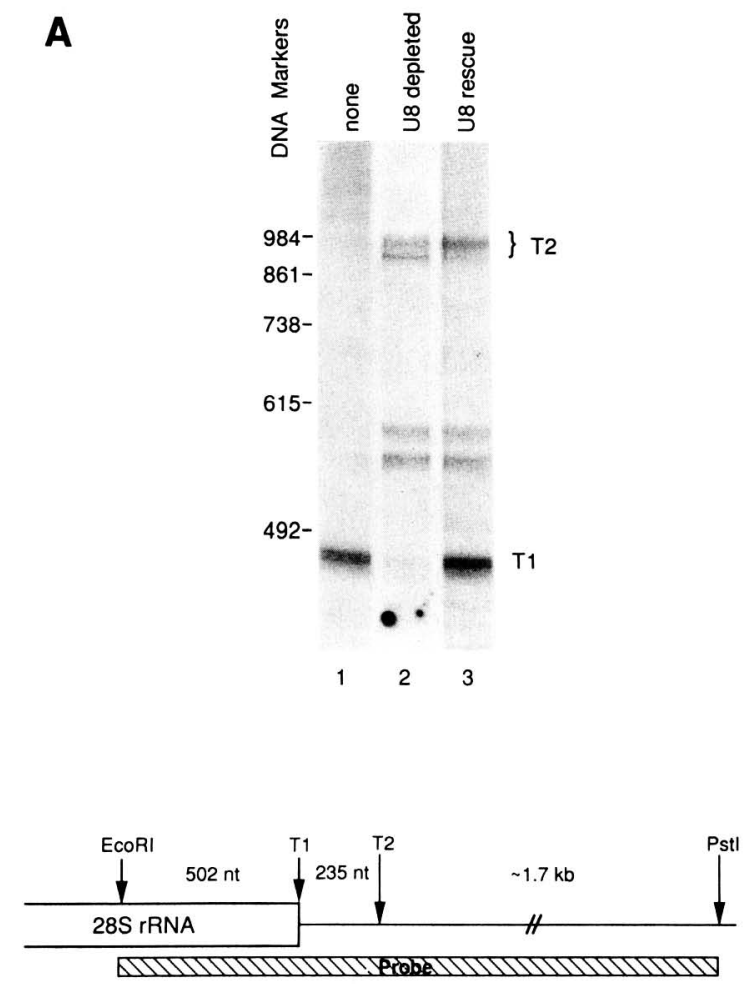

B
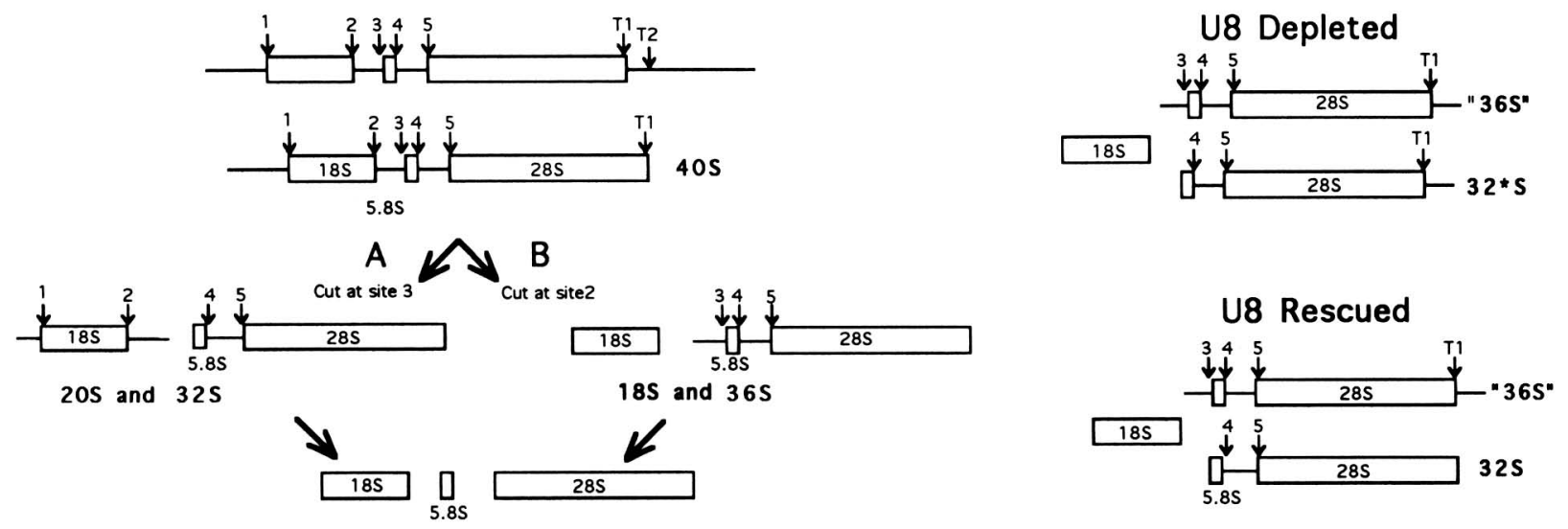

Figure 2. (A) S1 nuclease analysis of in vivo-labeled rRNAs. S1 digestion pattern produced after in vivo-labeled RNA from untreated oocytes (lane 1), U8 RNA-depleted oocytes (lane 2), or U8-depleted oocytes subsequently injected with G-capped U8 RNA (U8 rescue) (lane 3) was annealed with an unlabeled probe extending from within the $3^{\prime}$ end of $28 \mathrm{~S}$ through part of the $3^{\prime}$ nontranscribed spacer region of the Xenopus rDNA repeat (bottom). Protected fragments corresponding to the correct $3^{\prime}$ end of $28 \mathrm{~S}$ rRNA (T1) and the $3^{\prime}$ extension present in U8-depleted oocytes (bracket, T2), to near T2 or beyond, are indicated. The numbers indicate the size of 123-bp DNA markers. The origin of the faint bands at $\sim 550$ nucleotides is not known. These highly reproducible bands may be attributable to either the presence of a processing site within the 3' ETS, or, more likely, nibbling by S1 nuclease. (B) Pre-rRNA processing pathways utilized in normal Xenopus oocytes, as well as in U8-depleted and U8-rescued oocytes.

36 rRNA. Figure 1 (lanes 2) contains in vivo-labeled RNA from oocytes previously depleted of their endogenous pool of U8 RNA. The typical U8-depleted rRNA processing pattern is seen: No mature $28 \mathrm{~S}$ rRNA is produced. Instead, " $36 \mathrm{~S}^{\prime \prime}$ and $32^{\star} \mathrm{S}$ rRNAs accumulate. These abnormal precursors to $28 \mathrm{~S}$ migrate slightly slower than their normal counterparts because of addi- tional nucleotides at the $3^{\prime}$ end of $28 \mathrm{~S}$ (Peculis and Steitz 1993). In addition, no 12S RNA (a long-lived nuclear precursor to 5.8S RNA) is observed (data not shown).

Figure 1 (lanes 3) contains RNA from oocytes, which like those in lanes 2, were depleted of their endogenous U8 RNA, but were subsequently microinjected with in vitro-synthesized G-capped U8 RNA. Oocytes will hy- 
permethylate snRNAs carrying the G-cap (Fischer and Lührmann 1990; Hamm et al. 1990a), whereas A-cap is not a substrate for hypermethylation (Baserga et al. 1992). The "rescued" rRNA processing pattern appears; mature $28 \mathrm{~S}$ rRNA is seen, and the normal form of $32 \mathrm{~S}$ accumulates. The " $36 S^{\prime}$ " rRNA is also present, although after rescue this precursor fails to produce the tight, well-defined band seen in untreated oocytes. In addition, the $12 \mathrm{~S}$ precursor to $5.8 \mathrm{~S}$ rRNA reappears (data not shown).

Figure 1 (lanes 4) contains RNA from oocytes depleted of their endogenous U8 RNA and later injected with U8 RNA capped with the A-cap dinucleotide. The rescued processing pattern shows mature $28 \mathrm{~S}$ rRNA (Fig. 1A,B, lanes 4), the normal form of $32 \mathrm{~S}$ (Fig. 1B, lane 4), as well as the normal $12 \mathrm{~S}$ rRNA intermediate (data not shown). These results, plus titration studies showing that the A-cap RNA functions as efficiently as the G-cap RNA (data not shown), indicate that the TMG cap normally present on U8 RNA is not essential for nuclear accumulation, particle assembly, nucleolar localization, or function of U8 RNP.

\section{$5^{\prime}$-End processing of $5.8 S$ and $3^{\prime}$-end processing} of $28 S$ RNAs are linked

When U8 RNA is injected into the cytoplasm of U8depleted oocytes, pre-rRNA processing is rescued; mature $28 \mathrm{~S}$ and the normal $32 \mathrm{~S}$ precursor to $5.8 \mathrm{~S}$ and $28 \mathrm{~S}$ appear. However, the gel mobility of $36 \mathrm{~S}$, the alternate precursor to $5.8 \mathrm{~S}$ and $28 \mathrm{~S}$, indicated that the rescue with respect to this species may not be complete. S1 nuclease analysis was performed on total RNA isolated from the nuclei of untreated (Fig. 2A, lane 1), U8-depleted (lane 2), or U8 G-cap RNA-rescued (lane 3) oocytes. As was seen previously (Peculis and Steitz 1993), in oocytes depleted of U8 RNA, processing fails to occur at site T1, leaving a sizable 3 ' extension on precursors to $28 \mathrm{~S}$ rRNA (Fig. 2A, lane 2; see Fig. 2B). In Xenopus oocytes, rRNA transcribed past T2 is highly unstable (Labhart and Reeder 1986), so we presume that the new $3^{\prime}$ end maps at or very near to site $\mathrm{T} 2$, which is 235 nucleotides downstream of T1.

Subsequent injection of U8 RNA restores $3^{\prime}$ termini at site $\mathrm{Tl}$, as evidenced by the normal migration of the $28 \mathrm{~S}$ and 32 S pre-rRNAs (Fig. 1B, lanes 3,4; see also Fig. 5A, below) and the reappearance of a normal band in the S1 nuclease protection assay (Fig. 2A, lane 3). However, the S1 assay also reveals that the longer RNAs seen in depleted oocytes do not disappear completely, even when the amount of U8 RNA injected is in fourfold excess of that needed for rescue of $32 \mathrm{~S}$ rRNA. Because the " $36 \mathrm{~S}^{\prime}$ " pre-rRNA appears as a thicker, more ill-defined band in rescued samples relative to untreated samples (Fig. 1B, lanes 3,4$)$, we propose that U8 RNA facilitates coordinate processing at sites 3 and $\mathrm{T} 1$ (Fig. $2 \mathrm{~B}$ ). If processing occurs at site 3 , cuts at site $\mathrm{T} 1$ will produce a normal $32 \mathrm{~S}$ species (Fig. 1B, lanes 3,4 ) with the correct $3^{\prime}$ terminus (Fig. 2A, lane 3). However, if processing at site 3 is debilitated (or if processing occurs at site 2 first), then there is inhibition of processing at Tl. Alternatively, it is possible that the initial inhibition of processing is at site $\mathrm{T} 1$, such that in the absence of processing at $\mathrm{T} 1$, no processing can occur at site 3 , causing site 2 to be utilized (see Fig. 2B).

\section{Site-directed mutagenesis produces U8 RNA mutants}

In generating mutants in U8 RNA (Fig. 3), we focused on conserved structures or nucleotides. The complete sequence of U8 RNA is shown at the top of Figure 3; uppercase letters indicate those nucleotides conserved between mammalian (Kato and Harada 1984; Reddy et al. 1985; Tyc and Steitz 1989) and Xenopus U8 (Peculis and Steitz 1993); lowercase letters represent nucleotides that are not identical. The $5^{\prime}$ end of the U8 RNA is highly conserved between Xenopus and mammals with only 4 nucleotide changes out of 38 . Likewise, the lengths of stems 1 and 2 are conserved. The conserved elements in the $3^{\prime} 100$ nucleotides include boxes $C$ and $D$, but neither the sequences nor the lengths of stem-loops 3 or 4 are conserved. The shaded nucleotides in Figure 3 indicate the nucleotides altered by site-directed mutagenesis (see Materials and methods) in each mutant; only the relevant portion of the U8 RNA is shown, the rest being the wild-type sequence.

The A-cap mutant, used above, is identical to the wildtype RNA with the exception of the cap itself. Another mutant $\left(5^{\prime}\right.$ end) changes the first 4 nucleotides in U8 to the complementary nucleotides. Several loop mutants (Lp1M, Lp1-23, Lp1-45, Lp2M, Lp2-13, Lp2-24, Lp3M, and $\mathrm{Lp} 4 \mathrm{M}$ ) changed selected nucleotides within the four predicted hairpin loops of U8 to nucleotides complementary to those in the wild type. For the first and second stems of U8 RNA, pairs of mutants (St1M5' and St1M3', St2M and St2M3') change the nucleotides on either side of the conserved stem $15^{\prime}$ and $3^{\prime}$, left and right side, respectively) to their complementary nucleotides; the compensatory mutants ( $\mathrm{St} 1 \mathrm{Mc}$ and $\mathrm{St} 2 \mathrm{C}$ ) change the sequence on both sides of the stem to restore base-pairing. Two mutants ( $C$ boxM and $D$ boxM) alter the conserved sequences in box $C$ and box $D$, respectively. The mutant $C$-upM changes the entire single-stranded region upstream of box $\mathrm{C}$, including several nucleotides conserved between mammals and Xenopus. Two additional mutants in this region change only those nucleotides that are conserved between Xenopus and human (C-upconM) or only those not conserved between these two species (C-upNC).

\section{Assaying hypermethylation and nuclear accumulation} of U8 mutants

Mutant U8 RNAs transcribed in vitro in the presence of $\left.{ }^{32} \mathrm{P}\right]$ UTP and the G-cap dinucleotide (except for the A-cap mutant/ were microinjected into the cytoplasmic compartment of oocytes. After incubation, the ability of each mutant RNA to accumulate within the nucleus, become hypermethylated, assemble into fibrillarin-pre- 


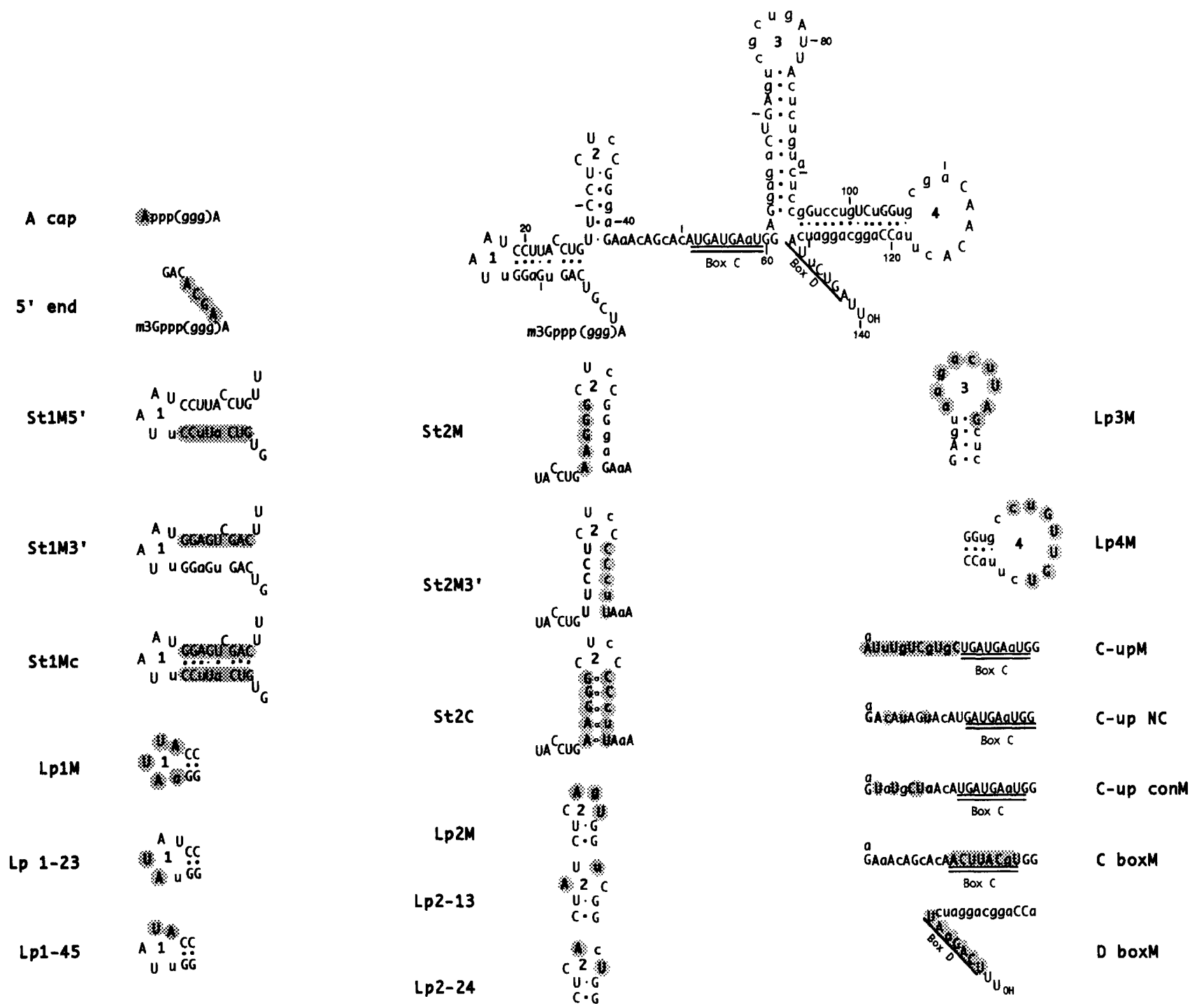

Figure 3. Mutant U8 RNAs generated by site-directed mutagenesis. (Top) The complete sequence of Xenopus U8 RNA is shown. (ggg) T7 transcription is enhanced by $3 \mathrm{G}$ nucleotides encoded on the templates for all exogenous U8 RNAs. Uppercase letters indicate positions conserved between Xenopus and mammals. Lowercase letters are nucleotides that have diverged. Below, the mutants generated by site-directed mutagenesis (Kunkel et al. 1987). For each mutant, only the relevant region of the U8 RNA is shown and the altered nucleotides are shaded.

cipitable particles, and function was analyzed. Clearly, if a mutant RNA was not stable in the cytoplasm, or could not accumulate within the nucleus, its function in prerRNA processing could not be assessed.

The amount of U8 RNA in the nuclear compartment of hand-dissected oocytes was compared with that remaining in the cytoplasm $6 \mathrm{hr}$ after injection. Figure 4A shows the results of a localization assay /summarized in Table 1). The A-cap mutant RNA accumulates in the nucleus as efficiently as the G-cap wild-type RNA (Fig. $4 A$, lanes $1,2,18,19 \mid$, and all other mutants are interpreted relative to these two RNAs. Most RNAs efficiently translocated to the nuclear compartment, with the exception of the Lp3M, C boxM, and D boxM mutants; these RNAs do not accumulate in the nucleus and degrade completely during a 14-hr incubation /data not shown|, although at the $6-\mathrm{hr}$ time point the $\mathrm{C}$ box and $\mathrm{D}$ box mutant RNAs are still detected in the cytoplasm (Fig. 4, A, lanes 11 and 28, 16 and 33, 17 and 34; C, lanes 12 and 31,17 and 36, 18 and 37). When injected into isolated nuclei, $\mathrm{Lp} 3 \mathrm{M}, \mathrm{C}$ boxM, and $\mathrm{D}$ boxM are likewise unstable.

The ability of each mutant to become hypermethylated was assayed by immunoprecipitation with antiTMG antibodies. Six hours after injection of ${ }^{32} \mathrm{P}$-labeled mutant RNAs into the cytoplasmic compartment, RNA was isolated from whole oocytes. The G-cap RNA was immunoprecipitated efficiently, whereas the A-cap RNA was not precipitated, as expected (Fig. 4B, lanes 1-4). The efficiency of immunoprecipitation by the anti-TMG an- 
A

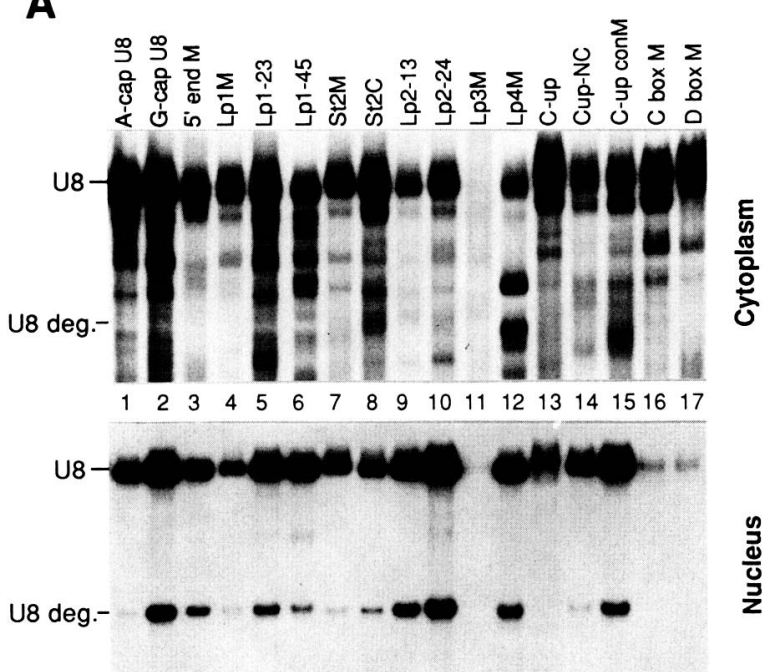

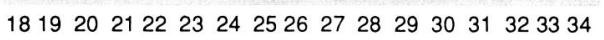

Figure 4. Assembly and stability of U8 RNA injected into U8-depleted oocytes. (A) Total RNA pooled from hand-dissected nuclei (bottom) and the corresponding cytoplasms (top) of oocytes that had received cytoplasmic injections of ${ }^{32} \mathrm{P}$-labeled in vitro-synthesized U8 RNA or mutant RNA indicated. $|B|$ Immunoprecipitations from extracts of whole oocytes injected with G-cap or A-cap U8 RNA (lanes 1-4) and of enucleated oocytes (lanes 5,6 ) or isolated nuclei (lanes 7-10) coinjected with G-cap U8 and U1 RNAs. (Lanes 1-8) Anti-TMG precipitations. (Lanes 9,10) Anti-fibrillarin immunoprecipitations from isolated nuclei identical to those used in lanes 7 and 8. Supernatants and pellets are indicated. (U8$\mathrm{deg}$ ) The stable $3^{\prime}$ end fragment of U8 RNA. (C) Anti-fibrillarin immunoprecipitations from extracts of whole oocytes microinjected with the mutant U8 RNAs. (Top) The supernatants from anti-fibrillarin precipitations; (bottom) the corresponding pellets. (Lanes 1-18) supernatants from whole oocytes injected with the ${ }^{32} \mathrm{P}$-labeled in vitro-transcribed mutant U8 RNA indicated; (lanes 20-37) the corresponding pellets. (Lanes 19,38) Supernatant and pellet, respectively, from enucleated oocytes injected with ${ }^{32} \mathrm{P}$-labeled in vitro-transcribed G-cap U8 RNA.

tibodies varies from RNA to RNA (Krainer 1988). In our hands, precipitation of naked U8 RNA is $\sim 50 \%$ efficient. Table 1 shows that all G-capped RNA mutants that were stable enough to be assayed also became hypermethylated. At shorter time points the $C$ boxM and $D$ boxM mutant RNAs present in the cytoplasm (Fig. 4A, lanes $16,17,33,34$ ) were not detectably hypermethylated (data not shown).

To determine the cellular location of hypermethylation, we hand-dissected injected oocytes and assayed the nuclear and cytoplasmic compartments separately. We find that of the U8 RNA remaining in the cytoplasm, only $\sim 10-20 \%$ is TMG-precipitable (data not shown) for both the wild-type (G-cap) and mutant RNAs. Conversely, $60-80 \%$ of U8 RNAs present within the nuclear compartment are TMG-precipitable. Whether this is because U8 RNPs typically are assembled in the cyto-
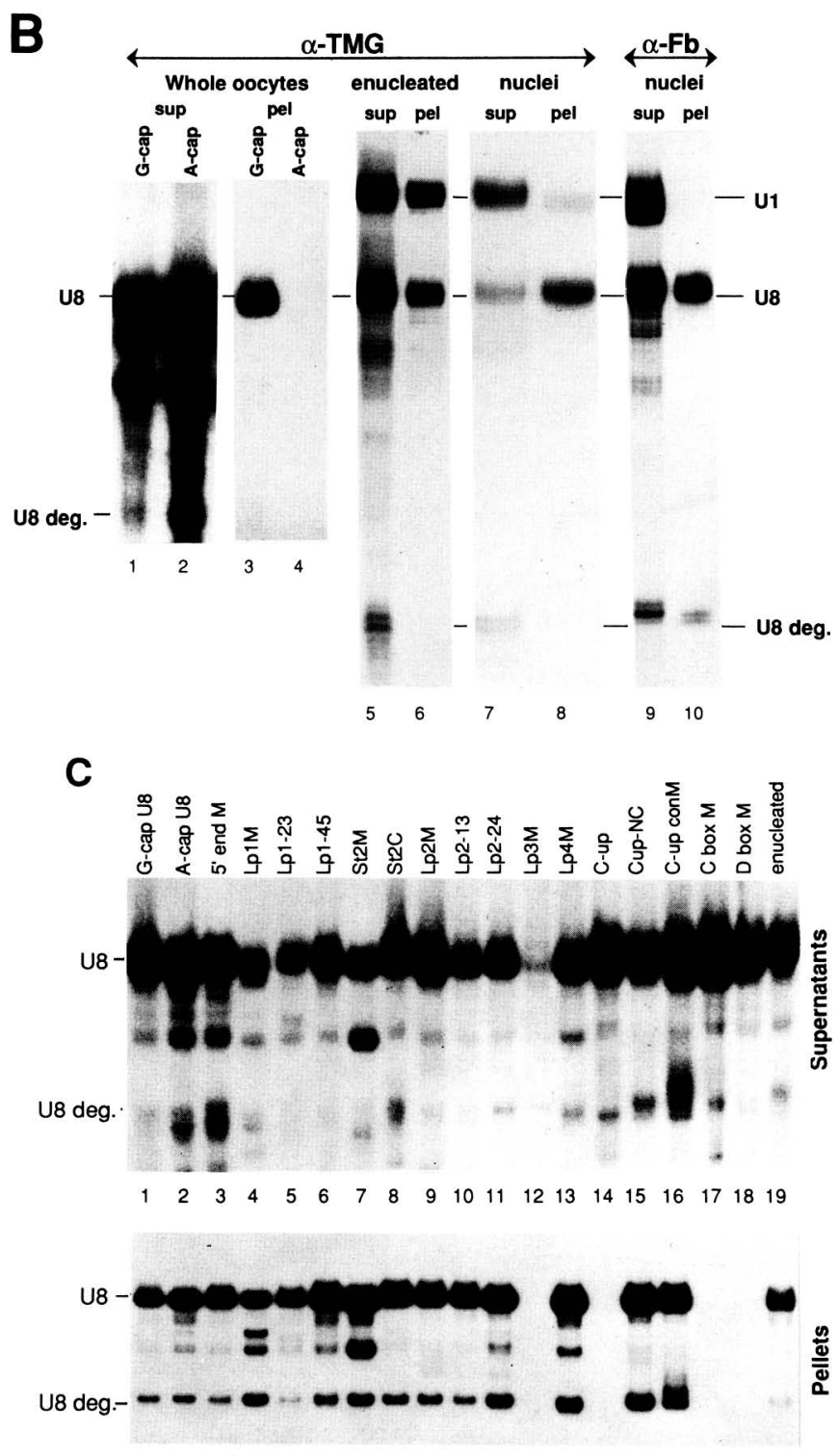

$\begin{array}{lllllllllllllllllll}20 & 21 & 22 & 23 & 24 & 25 & 26 & 27 & 28 & 29 & 30 & 31 & 32 & 33 & 34 & 35 & 36 & 37 & 38\end{array}$

plasm, become hypermethylated, and translocate into the nucleus immediately or because the hypermethylation activity is largely nuclear cannot be distinguished by this assay.

Therefore, we microinjected U8 RNA directly into isolated nuclei and assayed hypermethylation. Figure 4B shows the supernatants and pellets from anti-TMG precipitations of RNA isolated from enucleated oocytes (lanes 5,6$)$ or isolated nuclei (lanes 7,8$)$ coinjected with U8 and U1 RNAs. The U1 RNA, which can become hypermethylated only after assembling with the Sm proteins in the cytoplasm (Mattaj 1986), serves as a control for cytoplasmic contamination of the isolated nuclei. The TMG pellet of the enucleated sample (Fig. 4B, lane 6) shows that $20 \%$ of the U8 RNA and $22 \%$ of the U1 RNA become hypermethylated in the cytoplasmic compartment. In contrast, typically $65-80 \%$ of G-cap U8 in- 
Table 1. Summary of data on U8 mutants

\begin{tabular}{|c|c|c|c|c|}
\hline Mutant & $\begin{array}{l}\text { Nuclear } \\
\text { accumulation }^{\mathbf{a}}\end{array}$ & $\begin{array}{l}\text { TMG } \\
\text { precipitation }^{\mathrm{b}}\end{array}$ & $\begin{array}{l}\text { Fibrillarin } \\
\text { association }^{\mathrm{c}}\end{array}$ & $\begin{array}{l}\text { Rescue } \\
\text { processing }^{\mathrm{d}}\end{array}$ \\
\hline G-cap & ++ & ++ & + & + \\
\hline A-cap & ++ & - & + & + \\
\hline 5 '-end & ++ & ++ & + & - \\
\hline StlM5' & ++ & $1+1$ & $1+1$ & - \\
\hline St1M3' & + & & & - \\
\hline StlMc & + & $1+1$ & $1+1$ & - \\
\hline LplM & ++ & ++ & + & - \\
\hline Lpl-23 & ++ & $+t$ & + & + \\
\hline Lp1-45 & ++ & $+t$ & + & - \\
\hline St $2 M$ & + & + & + & - \\
\hline St2M3' & + & $1+1$ & $1+1$ & + \\
\hline St $2 \mathrm{C}$ & + & + & + & + \\
\hline Lp2M & + & + & + & - \\
\hline Lp2-13 & ++ & ++ & + & - \\
\hline $\mathrm{Lp} 2-24$ & ++ & ++ & + & - \\
\hline Lp3M & $+1-$ & ns & ns & ns \\
\hline $\mathrm{Lp} 4 \mathrm{M}$ & ++ & ++ & + & + \\
\hline C-up & + & + & - & - \\
\hline C-up-NC & ++ & ++ & + & + \\
\hline C-up-conM & ++ & ++ & + & - \\
\hline C boxM & $+1-$ & ns & ns & ns \\
\hline $\mathrm{D}$ boxM & $+1-$ & ns & ns & ns \\
\hline
\end{tabular}

Summary of data on U8 mutants. U8 RNA mutants were examined for their ability to accumulate within the nucleus, be precipitated with anti-TMG antibodies, be precipitated with anti-fibrillarin antibodies, and rescue rRNA processing in U8-depleted oocytes. $\mid++1$ Precipitates or accumulates to levels $>85 \%$ that of G-cap; (ns) RNA not stable in cytoplasm after 12 -hr incubation, $<15 \%$ of G-cap remains. Data are averages from three to six independent experiments, except those indicated by $\{+1$, which are single determinations; the data shown in the corresponding figures are representative. All RNAs were labeled to the same specific activity and identical amounts injected into each oocyte. Quantitation was done on a Molecular Dynamics PhosphorImager.

a $(+\mid 75-85 \%$ of G-cap level; $(+1-1<30 \%$ that of G-cap level.

$\mathrm{b}|+| 70-85 \%$ that of $\mathrm{G}-\mathrm{cap}_{i}|-|<3 \%$ of RNA precipitates.

$\mathrm{c}|+|>80 \%$ of G-cap; $(+1-1<80 \%$ of G-cap.

$\mathrm{d}\left(+\mid\right.$ The appearance of $28 \mathrm{~S}$ and conversion of $32 * S$ to $32 S_{;}(-)$inability of the mutant U8 RNA to alter the U8-depleted processing pattern; (ns) unstable RNA, ability to rescue cannot be determined.

jected into isolated nuclei is precipitated by anti-TMG antibodies, whereas $<9 \%$ of U1 RNA is precipitated from these same nuclei (Fig. 4B, lanes 7,8 ). U3 snRNA becomes hypermethylated in both the cytoplasmic (Baserga et al. 1992) and nuclear compartment (Terns and Dahlberg 1994) of Xenopus oocytes. Similarly, we conclude that U8 RNA can become hypermethylated in the cytoplasm, but cap modification is far more efficient in the nucleus.

\section{Assaying the assembly of mutant U8 RNAs into particles}

The ability of the mutants to assemble into RNP complexes was assayed indirectly by immunoprecipitation with anti-fibrillarin antibodies. Mutant ${ }^{32}$ p-labeled U8 RNAs were microinjected into the cytoplasmic compartment of oocytes. After a 4-hr incubation, whole oocyte extracts were prepared and the fraction of fibrillarin-precipitable mutant U8 RNA determined. Most of the mutant RNAs were precipitated efficiently with anti-fibrillarin antibodies (Fig. 4C). The major exceptions were the Lp3M, C-upM, C boxM, and D boxM mutant RNAs (lanes 12 and 31, 14 and 33,17 and 36, 18 and 37). It is important to note that the C-upM RNA is stable and accumulates in the nucleus (Fig. 4A, lanes 13,30 ), yet none of this RNA detectably associates with fibrillarin (Fig. 4C, lanes 14,33).

The $\mathrm{C}$ boxM and $\mathrm{D}$ boxM mutant RNAs are generally less stable in the cytoplasm than the G-cap RNA. By microinjecting larger quantities (up to twofold) of $\mathrm{C}$ box, and D box RNAs into the cytoplasm, and taking shorter time points (a 4-hr incubation), these RNAs could be assayed for fibrillarin association (Fig. 4C, lanes $17,36,18,37)$. Even then, only a very small fraction $|<5 \%|$ of these two mutant RNAs was precipitable, indicating that boxes $C$ and $D$ are essential for fibrillarin binding in vivo, as concluded previously in vitro (Baserga et al. 1991). These results suggest further that fibrillarin binding and cytoplasmic stability may be linked.

Oocytes were also hand-dissected prior to analysis, and the fibrillarin-associated mutant U8 RNA present in the nuclear or cytoplasmic compartments was examined separately (data not shown). These experiments showed that fibrillarin-associated mutant U8 RNAs were present in both compartments, but the majority was in the nu- 
cleus. This assay cannot distinguish between rapid import of fibrillarin-associated U8 RNA and fibrillarin binding occurring within the nucleus after import. The fact that there are fibrillarin-associated, intron-encoded nucleolar snRNAs that have not been shown to have a cytoplasmic phase (Liu and Maxwell 1990; Fragapane et al. 1993; Prislei et al. 1993; Tycowski et al. 1993; K. Tycowski, pers. comm.) is consistent with the observations of Caizerguez-Ferrer et al. (1991), who report a pool of fibrillarin in the oocyte nucleus.

To determine whether U8 RNA can associate with fibrillarin in separated nuclear and cytoplasmic compartments, we microinjected U8 RNA into enucleated oocytes and incubated them prior to making an extract for immunoprecipitation with anti-fibrillarin antibodies. Similar fractions of U8 RNA (typically $\sim 35-50 \%$ ) were precipitated in the absence of a nucleus (Fig. $4 \mathrm{C}$, lanes 19,38 ) and from a whole oocyte (Fig. 4C, lanes 1,20), indicating that U8 RNA can associate with fibrillarin in the cytoplasm. Subsequently, U1 plus U8 RNAs were microinjected into isolated nuclei, incubated for $4 \mathrm{hr}$, and used to make extract. Typically, $\sim 50 \%$ of the U8 RNA was fibrillarin precipitable (Fig. 4B, lanes 9,10), whereas U1 RNA, which does not associate with fibrillarin, failed to precipitate $(<1 \%)$. We conclude that fibrillarin association can occur in the nucleus, but the C-up mutant (Fig. 4C, lanes 14,33) shows that fibrillarin binding is not necessary for nuclear accumulation of $U 8$ RNA.

The anti-fibrillarin immunoprecipitations revealed two forms of U8 RNA stably associated with fibrillarin in the nucleus of U8-injected oocytes (Fig. 4B, lanes 9,10; C). One RNA was full length, whereas the other band was a stable fragment apparently corresponding to the $3^{\prime}$ end of U8 [as it is not anti-TMG precipitable (Fig. 4B, lanes 1-8)]. The length of the fragment $(\sim 100$ nucleotides) suggests that it is produced by cleavage of U8 RNA within the single-stranded region upstream of box C.

\section{Some mutant U8 RNAs can rescue rRNA processing}

Each in vitro-synthesized ${ }^{32} \mathrm{P}$-labeled G-cap mutant RNA was microinjected into the cytoplasmic compartment of U8-depleted oocytes, followed $4 \mathrm{hr}$ later by $\left[{ }^{32} \mathrm{P}\right] \mathrm{UTP}$ to label nascent RNAs. As indicated in Table 1 , some mutants were able to rescue rRNA processing while others were not. Figure 5, A and B, shows the rescue of rRNA processing by some of the mutants, compared with the A-cap (lanes 3) and the G-cap (lanes 4) wild-type U8 RNAs.

The $5^{\prime}$ end mutant (altered in nucleotides $2-5$ of U8 RNA) is defective in rRNA processing (Fig. 5A, lane 12). Likewise, the Lp1M mutant, which has all 5 of the nucleotides in the first loop of U8 altered, does not function (lane 13). The same is true of Lpl-45 in which only 2 of these 5 nucleotides are changed (lane 15). However, the Lp1-23 mutant (lane 5), in which the other 2 of the 5 nucleotides in the first loop of U8 RNA are changed, can function in rRNA processing. In contrast, mutations in the fourth loop (Lp4M mutant) did not affect rescue of rRNA processing (lane 8) even though 7 of 10 nucleotides were altered, including 5 that are conserved between mammals and Xenopus.

There is scattered conservation of sequence in the single-stranded region of U8 RNA upstream of box C. Changing all 10 nucleotides in this region renders $\mathrm{U} 8$ nonfunctional, as does changing only the nucleotides conserved between mammals and Xenopus [C-up and C-up-conM (Table 1), respectively]. However, changing 3 of the 4 nucleotides not conserved between these two widely diverged vertebrates (C-up-NC) yields a functional RNA (Fig. 5A, lanes 9,18).

The first and second stems predicted for U8 RNA are conserved in structure, and partly in sequence, between Xenopus and mammals (Kato and Harada 1984; Reddy et al. 1985; Tyc and Steitz 1989; Peculis and Steitz 1993). In the mutants StlM5' and StlM3' (Fig. 3) this conserved structure is destroyed and the RNA is not functional (data not shown). The compensatory mutant, StlC, restores the base-pairing but remains nonfunctional. We conclude that the positions of the evolutionarily conserved sequences within this structure are critical.

The sequence of the 5' side of U8 RNA's second stem is evolutionarily conserved while the $3^{\prime}$ side is not (Fig. 3). St2M alters the conserved nucleotides and is not functional (Fig. 5A, lane 6). St2M3' alters the nonconserved nucleotides and does function, but less efficiently /data not shown). The compensatory mutant, St2C, restores the structure of the stem and functions, but less efficiently (lane 7) than the wild type (lane 4). Therefore, we conclude that the evolutionarily conserved sequence on the $5^{\prime}$ side of the second stem is important, but not critical, for function. In its absence, some function can be provided by creating a secondary structure. Thus, both the sequence and structure of stem 2 are important for optimal activity.

Figure 5B analyzes the lower molecular weight RNAs from the same oocytes as those shown in Figure 5A. The in vivo-labeled 5S rRNA serves as a control for loading while the $12 S$ pre-rRNA can be seen in untreated oocytes (lane 1) as well as in those lanes containing RNA from oocytes injected with mutant U8 RNAs that can rescue processing (lanes $3,4,5,7,8,9,14,18$ ). In addition, each lane shows the quantity of ${ }^{32}$ P-labeled mutant U8 RNA present in the nuclei of the oocytes analyzed in Figure 5A. Generally, the amount of U8 RNA present correlates with the ability of each mutant to rescue processing. The A-cap, G-cap, Lp4M, and C-upNC RNAs are abundant in the nuclei of oocytes in which rRNA processing is rescued (Fig. 5A,B, lanes 3,4,8,9; also 14,18). Mutant St2M RNA is an exception in that it does accumulate within the nucleus (albeit at lower levels), but does not rescue pre-rRNA processing.

Because a mutant RNA that does not accumulate within the nucleus cannot be expected to function, titration studies were performed to establish the minimum amount of U8 RNA necessary to rescue processing. Figure 6 shows the titration curve for the G-cap U8 RNA, along with two mutants that do and two that do 
A
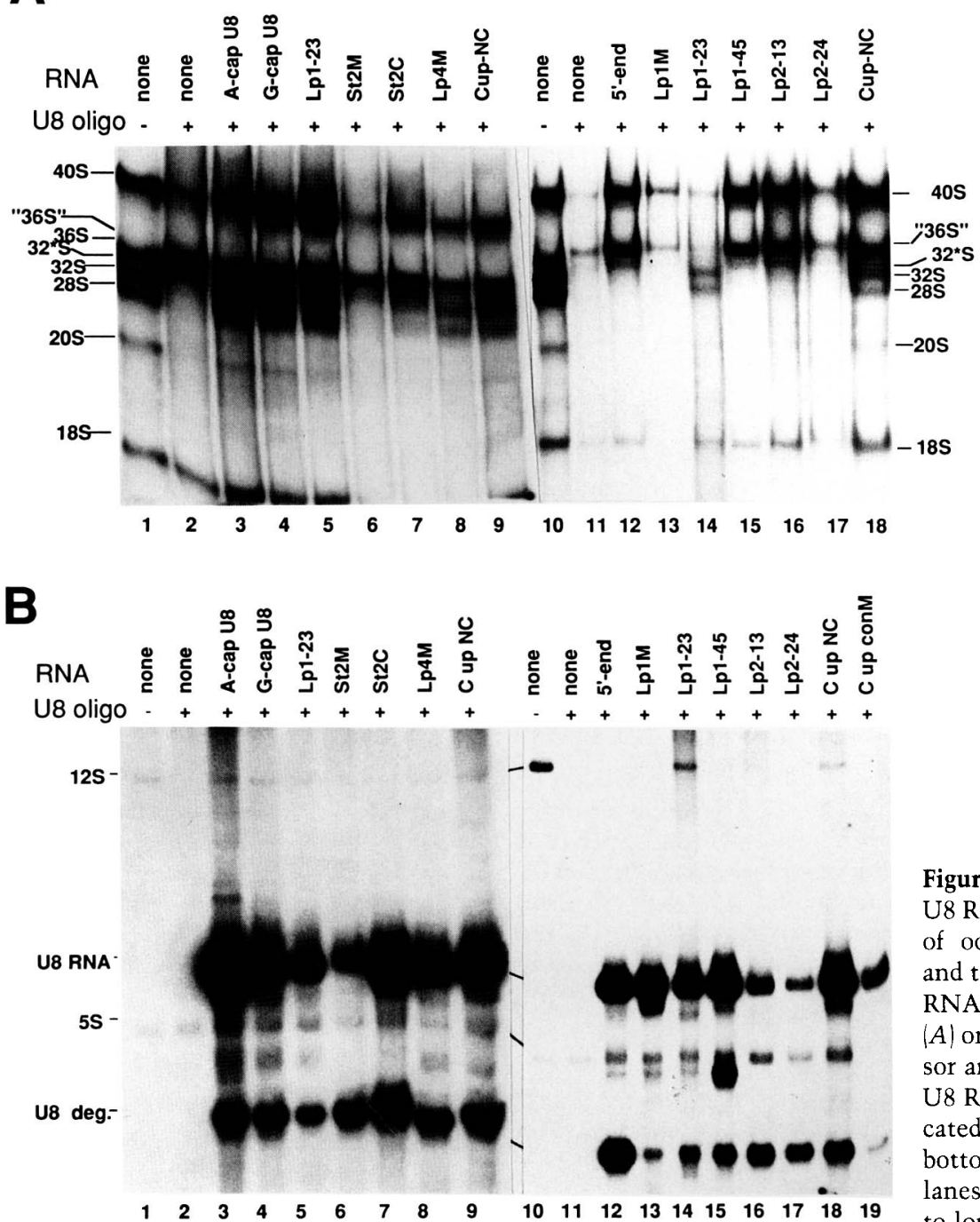

Figure 5. Rescue of rRNA processing with mutant U8 RNAs. In vivo-labeled RNAs isolated from nuclei of oocytes preinjected with deoxyoligonucleotide and then with in vitro ${ }^{32} \mathrm{p}$-labeled RNA as indicated. RNAs were resolved on $1 \%$ agarose-formaldehyde $(A)$ or $8 \%$ denaturing polyacrylamide $(B)$ gels. Precursor and mature rRNAs, and the in vitro-synthesized U8 RNA (and degradation product, U8 deg.) are indicated. In $A$, mature $18 \mathrm{~S}$ rRNA has run just off the bottom of the gel in lanes $6-9$. Longer exposures of lanes 11,13 , and 17 indicate that $18 \mathrm{~S}$ levels relative to longer precursors are normal.

not rescue rRNA processing. Controls show the "normal" rRNA processing pattern in untreated oocytes (Fig. $6 \mathrm{~A}$, lane 1 ) and the U8-depleted pattern (lane 2). Figure 6 (lanes 3-6) contains RNA from U8-depleted oocytes subsequently injected with $50 \mathrm{nl}$ of G-cap U8 RNA solution at concentrations representing $1 \times, 1 / 2 \times, 1 / 4 \times$ and $1 / 10 \times$ the amount of RNA used in Figure 5. Even at the lowest concentration of G-cap U8 RNA, rRNA processing was rescued; $28 \mathrm{~S}$ and $12 \mathrm{~S}$ rRNAs accumulated (Fig. 6A,B, lanes 5,6 ). The acrylamide gel (Fig. 6B) confirms that as less U8 RNA is injected into the cytoplasm, less accumulates in the nucleus (Fig. 6B, lanes 3-6).

Figure 6A (lanes 7-10) shows RNA from the nuclei of oocytes injected with $50 \mathrm{nl}$ of four different mutant RNAs, all at the $1 \times$ concentration. Lp1M RNA does not rescue rRNA processing (Fig. 6A, lane 7), although Figure $6 \mathrm{~B}$ shows that a sufficient quantity of RNA is present in the nucleus. Much less Lp1-23 RNA is present in the nucleus (about one-fifth); however, this RNA can rescue rRNA processing (lanes 8). A large quantity of St2C RNA accumulates in the nucleus and does function (lanes 9). Finally, there should be sufficient St2M RNA present in the nucleus (lanes 10), but rRNA processing is not rescued.

\section{Discussion}

Processing of $5.8 \mathrm{~S}$ and $28 \mathrm{~S}$ rRNAs is inhibited in Xenopus oocytes in the absence of U8 RNA, a hypermethylated, fibrillarin-associated, nucleolar snRNA. rRNA processing can be restored or rescued in U8-depleted oocytes by subsequent injection of in vitro-synthesized U8 RNA into the oocyte cytoplasm. We have examined nucleotides and structures within U8 RNA that are essential for its nuclear localization, assembly, and function in Xenopus oocytes.

\section{U8 functions without a TMG cap}

Transcription in the presence of an A-cap dinucleotide 

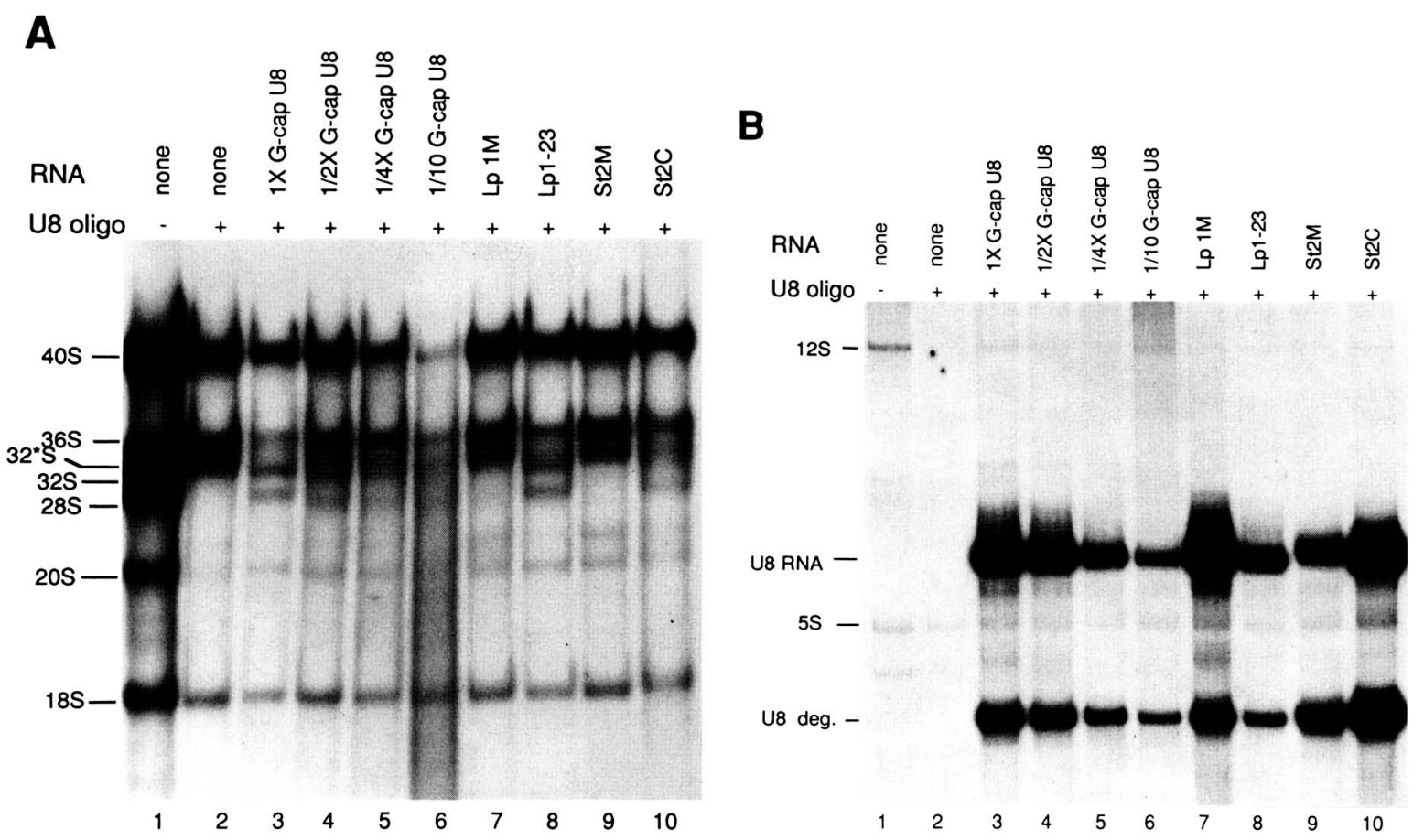

Figure 6. Titration of U8 RNA to examine function of mutant U8 RNAs. Rescue of rRNA processing was examined in U8-depleted oocytes microinjected with decreasing concentrations of ${ }^{32} \mathrm{P}$-labeled G-cap U8 RNA or mutant U8 RNAs \{at $1 \times$ concentration\} as indicated. In vivo-labeled RNAs isolated from the nuclei of treated oocytes, as indicated, were resolved on $1 \%$ agarose-formaldehyde $(A)$ or $8 \%$ denaturing polyacrylamide $(B)$ gels. Precursor and mature rRNAs, in vitro-synthesized U8 RNA, and a degradation product (U8 deg.) are indicated. Titration of the A-cap U8 RNA (not shown) gave a nearly identical processing pattern; partial rescue was seen at the $1 / 4 \times$ amount of RNA. The slightly altered migration of mature $28 \mathrm{~S}$ in lane 3 , compared with 4 and 5 is attributable to a loading difference (note that other bands in lane 3 are also shifted slightly upwards).

produces RNAs with a cap that is not a substrate for hypermethylation (Baserga et al. 1992). Yet, microinjection of the A-cap U8 RNA into oocytes produces fibrillarin-precipitable RNAs that can rescue rRNA processing (Fig. 1). Titration experiments using as little as $0.1 \times$ RNA showed that the A-cap RNAs function as effectively as the G-capped RNA (data not shown). The A-cap RNA must contain the A-cap dinucleotide (rather than G-cap) at its 5' end, as it does not become precipitable by the TMG antibodies (Fig. 4B, lanes 1-4). Also it is as stable as the G-capped RNA, whereas U8 RNAs synthesized in the absence of a cap analog are rapidly degraded $1<5 \%$ remains after $6 \mathrm{hr}$ ) when injected into the cytoplasmic compartment of oocytes (data not shown). We conclude that the TMG cap is not necessary for assembly or function of the U8 RNP.

Although previous work examined the requirement of a TMG cap for nuclear import of Sm snRNAs (Mattaj 1986, 1988; Fischer and Lührmann 1990; Hamm et al. 1990a; Baserga et al. 1992; Fischer et al. 1993; Marshallsay and Lührmann 1994|, our analyses are the first to demonstrate that a normally hypermethylated snRNA can function without a TMG cap. This is not to imply that the TMG cap plays no role in the U8 snRNP. The hypermethylated cap may be needed to regulate nuclear import, or prevent cytoplasmic retention after mitosis, as was seen with a G-capped U6 RNA /Fischer and Lü- hrmann 1990). Likewise, the TMG cap may be dispensable for U8 function in the Xenopus oocyte, but essential in somatic cells. Marshallsay and Lührmann (1994) showed recently that U1 can be imported into the nucleus of a somatic cell independent of a TMG cap, which is required for import in oocytes (Mattaj 1988; Fischer and Lührmann 1990).

\section{Location of particle assembly and hypermethylation of U8 RNA}

In most of our experiments we microinjected in vitrosynthesized U8 snRNA into the cytoplasmic compartment of oocytes. This procedure was chosen because cytoplasmic injections produce more uniform results and, unlike nuclear injections, cause no mechanical damage that may complicate interpretation of the data because of leakage from the nucleus. U6 snRNA, the only RNA polymerase III transcript in the functional spliceosome (Dahlberg and Lund 1988), does not leave the nucleus after transcription, whereas the other spliceosomal snRNAs do (Hamm and Mattaj 1989; Vankan et al. 1990). Likewise, the biogenesis of the U3 snRNP does not appear to have a cytoplasmic phase (Terns and Dahlberg 1994). Yet, when U6 or U3 RNA is injected into the cytoplasm of Xenopus oocytes, it can localize to the nucleus (Hamm and Mattaj 1989; Baserga et al. 1992), pre- 
sumably mimicking the relocalization that occurs following mitosis. We argue that assembly, import, and function of U8 RNA introduced via cytoplasmic injections likewise utilize normal physiological pathways. All mutant U8 RNAs that were stable accumulated in the nucleus (Table 1), allowing their function to be assessed.

Microinjection of in vitro-transcribed RNAs into either enucleated oocytes or into isolated nuclei indicated that fibrillarin association can occur in both compartments, yet the site of fibrillarin binding is not necessarily that of U8 particle assembly as other U8-specific proteins (that have not yet been identified) may be required to bind before fibrillarin. The C-upM mutant is a stable RNA that does not bind fibrillarin, suggesting that while the stability of U8 may be enhanced by fibrillarin binding, the presence of other (perhaps U8-specific) proteins can stabilize this mutant RNA in the absence of fibrillarin. This would contrast with the situation for the Sm snRNPs, where partial particle assembly with the common Sm proteins occurs prior to nuclear import, with additional specific proteins (that enter the nucleus independent of the RNP) binding after translocation (Hamm et al. 1990b; Kambach and Mattaj 1992; Jarmolowski and Mattaj 1993). A steady-state pool of fibrillarin has been identified in the nucleus of hand-dissected Xenopus oocytes (Caizergues-Ferrer et al. 1991). However, because these analyses were performed by Western blot, it is not known how much of this pool represents RNAassociated protein or where a pool of free fibrillarin might reside in the cell. Mutants $\mathrm{C}$ boxM and $\mathrm{D}$ boxM are unstable over long ( $>6 \mathrm{hr}$ ) incubations. We have shown that at $6 \mathrm{hr}$, when some RNA is still present, fibrillarin does not detectably associate with these RNAs, although we do not know whether the instability is the result of an absence of other proteins that normally bind boxes $\mathrm{C}$ and $\mathrm{D}$ directly. These data constitute the first in vivo indications that boxes $C$ and $D$ are necessary for fibrillarin binding in vertebrates.

Like fibrillarin binding, hypermethylation of G-cap U8 RNA occurs after microinjection into either enucleated oocytes or isolated nuclei, although cap modification is more efficient in the nucleus. Previous work with U3, a relatively more abundant hypermethylated fibrillarin-associated nucleolar snRNA, indicates that it also can become hypermethylated in both the cytoplasmic (Baserga et al. 1992) and nuclear (Terns and Dahlberg 1994) compartments of oocytes.

\section{The $5^{\prime}$ domain of U8 RNA is essential for function}

The $5^{\prime}$ one-third (40 nucleotides) of U8 RNA is $90 \%$ identical between Xenopus and mammals. Such a high degree of conservation through evolution is often indicative of selection based on function. For example, the most highly conserved regions in U1, U2, U5, and U6 snRNAs are those involved in snRNA-snRNA or snRNA-substrate interactions (for review, see Moore et al. 1993). Our data indicate that most of the U8 mutations in the $5^{\prime}$ domain (including the first two stem-loops) of the RNA were deleterious; only 4 of the 14 mutants affecting the first 39 nucleotides could function /see Table 1). The addition of the three guanosine residues at the $5^{\prime}$ end of U8 RNA (to enhance T7 transcription in vitro) did not prevent the RNA from functioning, although we cannot be sure that efficiency was not affected.

Mutations in most of the predicted single-stranded regions in the $5^{\prime}$ domain of U8 RNA gave processing negative phenotypes. These include the extreme $5^{\prime}$ end of the molecule as well as the loops of the first two stems. One mutant (Lp1-23) identified two conserved nucleotides in the first loop of $\mathrm{U} 8$ that could be changed without affecting function, but alteration of additional nucleotides in this loop resulted in a nonfunctional RNA. Extensive mutational studies on $\mathrm{U} 1$ and $\mathrm{U} 2$ have likewise identified sequence elements essential for specific steps in splicing (Hamm et al. 1988, 1989; 1990b; Ares and Igel 1990; Pan and Prives 1989; Zavanelli and Ares 1991; McPheeters and Abelson 1992).

Mutation of the first two stem structures of U8 demonstrates that they both contain essential elements for efficient functioning. In stem 1 , altering either the $5^{\prime}$ or $3^{\prime}$ side abolishes function; restoring the structure is not sufficient to restore rRNA processing. However, for the second stem of $U 8$, altering the $3^{\prime}$ side $\left(\mathrm{St}_{2} \mathrm{M}^{\prime}{ }^{\prime}\right)$, which destroys the structure but leaves intact the evolutionarily conserved nucleotides, gives a functional (albeit less efficient) RNA. Interestingly, the compensatory mutation, which restores the base-pairing but eliminates the conserved sequence $(\mathrm{St} 2 \mathrm{C}$ ), also functions (about as well as St2M3') showing that a stem structure can somehow substitute for the missing conserved sequence. Similarly, in U2 snRNA, mutation of critical secondary structures produced nonfunctional RNAs, whereas compensatory mutations restoring structure also restored function (Hamm et al. 1989; Ares and Igel 1990; Zavanelli and Ares 1991). In particular, stem 1 of U2 snRNA (McPheeters and Abelson 1992) is similar to stem 2 of U8 RNA in that structure is important but not absolutely essential for function. In U8 RNA the evolutionarily conserved nucleotides on the $5^{\prime}$ side of this stem also affect efficiency.

The remaining two-thirds of U8 RNA is not evolutionarily conserved and was not mutated as extensively for these studies. Several of the mutations yielded RNAs that were unstable upon injection into either the cytoplasm or isolated nuclei (data not shown); these RNAs (Lp3M, C boxM and D boxM) could not be assessed for function. The only mutations that did affect the function of stable, nuclear accumulated RNAs affected conserved nucleotides in the single-stranded region just upstream of box $\mathrm{C}$ (nucleotides $42-50$ ). Less than $40 \%$ of the eighty 3 '-most nucleotides are conserved between Xenopus and mammals. The stable 100-nucleotide $3^{\prime}$ U8 RNA fragment that remains after oligonucleotide targeting of the endogenous U8 (Peculis and Steitz 1993) is anti-fibrillarin precipitable but nonfunctional. Thus, in the absence of the $5^{\prime}$ end of U8, fibrillarin binding is not sufficient for function. These results argue that the $5^{\prime}$ do- 
main of U8 RNA is probably the most critical for function.

\section{How does the $5^{\prime}$ end of U8 function in pre-rRNA processing?}

It is possible that base-pairing between U8 RNA and Xenopus pre-rRNA sequences directs the U8 snRNP to its sites of action. However, no complementarity longer than 6 nucleotides exists within 100 nucleotides of either site 3 or $\mathrm{T} 1$ to a region in U8 available to RNase $\mathrm{H}$ cleavage (thus, exposed on the U8 particle). Because even a critical interaction might be only a few base pairs long, other types of experiments [e.g., cross-linking, used to identify U3 binding within the $5^{\prime}$ external transcribed spacer (ETS) (Stroke and Weiner 1989; Tyc and Steitz 1992)] will be needed to analyze U8-pre-rRNA interactions.

There is an intriguing complementarity $(13 / 17$ nucleotides) between Xenopus U8 RNA and pre-rRNA nearly 200 nucleotides downstream of $\mathrm{T} 1$ :

This interaction would predict that all loop 2 mutants

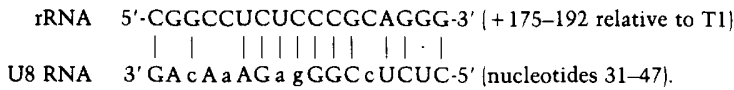

(Lp2M, Lp2-13, and Lp2-24) would be nonfunctional, and the data (Table 1) indicate that they are. However, changes in the $3^{\prime}$ portion of stem 2 (nucleotides $37-42$ ) should also be nonfunctional, as this region forms the core of the above complementarity. Rather, the ability of the St2M3' and St2C mutant RNAs to function (Table 1) shows that this sequence is nonessential and argues against this computer-identified complementarity as a site of U8-pre-rRNA interaction. Moreover, a corresponding complementarity cannot be identified between U8 and pre-rRNA at a conserved distance from the 3 ' end of $28 \mathrm{~S}$ in mammals (Kato and Harada 1984; Reddy et al. 1985; Tyc and Steitz 1989).

An alternative explanation for the processing-negative phenotypes of the mutations affecting the $5^{\prime}$ domain of U8 is that they interfere with protein binding, either directly or by inducing structural changes. For instance, the processing defects caused by mutations in loops 1 and 2 of U8 RNA are reminiscent of mutations in loop sequences of U1 RNA (Hamm et al. 1988, 1990b) or U2 RNA (Wells and Ares 1994) that direct specific protein binding. Further investigation will be required to establish the identity of such U8 proteins and their roles in U8 function.

\section{The U8 RNP affects processing at two sites} in the pre-rRNA

In Xenopus pre-rRNA processing, cleavage at site 2 or 3 determines which precursors to $28 \mathrm{~S}$ rRNA will accumu- late (Fig. 2B). Cleavage at site 2 produces mature $18 \mathrm{~S}$ and $36 \mathrm{~S}$ rRNAs, the latter of which is processed to yield $12 \mathrm{~S}$ and $28 \mathrm{~S}$ rRNAs, whereas cleavage at site 3 yields $20 \mathrm{~S}$ and $32 \mathrm{~S}$ rRNAs, the latter of which is processed to $12 \mathrm{~S}$ and $28 \mathrm{~S}$ rRNAs. In U8-depleted oocytes, no detectable cleavage occurs at T1 (Fig. 1A and 5A), which is normally a very rapid event (Labhart and Reeder 1986). This leaves a $3^{\prime}$ extension present on all precursors of 28S RNA (thereby producing shifts in mobility of the $32^{\star} S$ and "36S" rRNAs). Moreover, in U8-depleted oocytes, cleavage is very inefficient at site 3 , increasing the amount of " $36 S^{\prime}$ ". We do not know whether the 5 ' end of the $32^{\star} \mathrm{S}$ has been produced in the normal way or by exonucleolytic action on "36S." When U8-depleted oocytes are rescued by injection of U8 RNA, normally migrating $32 \mathrm{~S}$ and 28 S rRNAs appear (see Fig. 2B), indicating that all RNAs cleaved at site 3 have also been processed at $\mathrm{T} 1$. However, the " $36 S^{\prime}$ " species remains, suggesting that cleavage near site 2 precludes subsequent processing at site T1. Perhaps if cleavage at T1 and site 2 do not occur in the normal order, an alternate RNA secondary/tertiary conformation forms that makes $\mathrm{Tl}$ unrecognizable, or unavailable, to the processing machinery.

In the titration experiments, the inability to completely rescue coordinated processing at $\mathrm{T} 1$ and site 3 by injection of U8 may be the result of a lack of sufficient U8 RNA. Decreasing the amount of wild-type G-capped U8 RNA injected by fourfold resulted in a partial rescue phenotype, where some mature $28 \mathrm{~S}$ rRNA accumulated. However, the aberrant pre-rRNAs were also present (Fig. 6). Specifically, the conversion from $32^{\star} S$ to $32 S$ was not complete, resulting in the appearance of four bands ("36S", 32*S, 32S, and 28S; see Fig. 2B) in this region of the gel (Fig. 6A, lanes 4,5). If only enough U8 is added to restore processing at some $\mathrm{Tl}$ sites, then only these prerRNAs will undergo normal cleavage at site 3 . Because U8 and U3 (and possibly several other) RNPs affect prerRNA processing at site 3 (Savino and Gerbi 1990; Hughes and Ares 1991; Peculis and Steitz 1993), they may act together; depleting the system of one of these components would be expected to alter the efficiency at which that site is utilized and could indirectly determine which of the alternative processing pathways are used.

The inability to restore completely normal migration to "36S" rRNA, yet produce normal 32S RNA, indicates that in Xenopus, like yeast, cleavages at sites $3^{\prime}$ of $28 \mathrm{~S}$ and $5^{\prime}$ of $5.8 \mathrm{~S}$ (site 3, see Fig. 2B) are in some way linked (Veldman et al. 1981; for review, see van Nues et al. 1993). Because eukaryotic 5.8S rRNA corresponds to the 160 nucleotides at the $5^{\prime}$ terminus of prokaryotic $23 \mathrm{~S}$ rRNA (Brosius et al. 1979), the coordinate processing that occurs at the $3^{\prime}$ end of $28 \mathrm{~S}$ and the $5^{\prime}$ end of $5.8 \mathrm{~S}$ also parallels the cleavages that are made by RNase III in Escherichia coli. There, processing is directed by extensive base-pairing of the pre-rRNA flanking both $16 \mathrm{~S}$ and 23S sequences (Young and Steitz. 1979; Bram et al. 1980). No extensive base-pairing of this type can be discerned in eukaryotic pre-rRNA sequences. Yet, the $5^{\prime}$ end of $5.8 \mathrm{~S}$ and the $3^{\prime}$ end of $28 \mathrm{~S}$ rRNAs could be brought into close proximity by base-pairing between the flanking se- 
quences in yeast pre-rRNA (Veldman et al. 1981). No U8 RNA homolog has yet been identified in yeast.

Relative to the splicing snRNPs (for review, see Baserga and Steitz 1993; Moore et al. 1993), little is known about how the nucleolar snRNAs interact with each other and with the pre-rRNA to achieve efficient processing (for review, see van Nues et al. 1993). Correct folding and processing requires an ordered assembly with specific ribosomal proteins (Finley et al. 1989; Raue and Planta 1991), nonribosomal proteins (Jansen et al. 1991; Tollervey et al. 1991; Girard et al. 1992), and presumably nucleolar snRNPs. The role of nucleolar snRNPs in prerRNA processing is slowly being unveiled. By learning more about each nucleolar snRNA, how it assembles, and what is important for function, we hope to define the interactions that produce mature ribosomal subunits in vertebrates.

\section{Materials and methods}

\section{Antibodies}

Anti-TMG antibodies (Krainer 1988) were obtained from Oncogene Science (Manhasset, NY). Anti-fibrillarin monoclonal antibody (Reimer et al. 1987) was a gift from Eng Tan and Michael Pollard (Scripps Clinic, La Jolla, CA).

\section{Preparation of oocytes for immunoprecipitations}

Preparation of oocytes was essentially as described (Peculis and Steitz 1993) except that whole oocytes, enucleated oocytes, or isolated nuclei were disrupted in NET200 $140 \mathrm{~mm}$ Tris at $\mathrm{pH} 7.5$, $200 \mathrm{mM} \mathrm{NaCl}, 0.05 \% \mathrm{NP}-40$ ) with the final $\mathrm{NaCl}$ concentration adjusted to $400 \mathrm{~mm}$. Disruption was achieved by pipetting $8-10$ oocytes, cytoplasms, or nuclei, five times through a P-200 pipette tip. Following centrifugation for $10 \mathrm{~min}$ at $15,000 \mathrm{rpm}$, the cleared extract was used for immunoprecipitation with antifibrillarin antibodies. For anti-TMG immunoprecipitations, the cleared extract was extracted with phenol/chloroform/isomyl alcohol (25:24:1) twice, precipitated with ethanol, and redissolved in NET200. All precipitations were performed in NET200, using protein A-Sepharose (Pharmacia) incubated previously with the appropriate antibody. The recovered RNAs were resolved on $8 \%$ denaturing polyacrylamide gels.

\section{Deoxyoligonucleotides}

Deoxyoligonucleotides, provided by John Flory (Yale University, New Haven, CT) were synthesized on an Applied Biosystems DNA synthesizer. The following deoxyoligonucleotides were used for site directed mutagenesis: U8-5' end, 5'-GATTAACCTCACTGTGTCTCCCTATAGTGAG-3'; U8-St1M5', 5'-GATTAATACGACTCACTATAGGGATCGTGTCATTCCTTAATCCTTACCTGTTCCTCTCC-3'; U8-St1M3', 5'-GATTAATACGACTCACTATAGGGATCGTCAGTGAGGTTAATGGAGTCGACTTCCTCTCCGGG-3'; U8-St1C, 5'-GATTAATACGACTCACTATAGGGATCGTGTCATTCCTTAATGGAGTCGACTTCCTCTCCGGG-3'; U8-LplM, 5'-GGAACAGGTAAGGTAATTCCTCACTGACG-3'; U8-Lpl-23, 5'-GGAACAGGTAAGGATATACCTCACTGACG-3'; U8-Lpl-45, 5'-GGAACAGGTAAGGGGTAACCTCACTGACG-3'; U8St2M，5'-CATCATGTGCTGTTTCTCCCGGAGCCCTTCAGGTAAGG-3'; U8-St2M3， 5'-CATCATGTGCTGTTTAAGGGGGAGAGGAACAGGTAAGG- ${ }^{\prime}{ }^{\prime}$; U8-St2C， 5'-CAT-
GTGCTGTTTAAGGGGGAGCCCTTCAGGTAAGGATT- ${ }^{\prime}$; U8-Lp2M， 5'-GCTGTTTCTCCCACTCAGGAACAGG-3'; U8-Lp2-13, 5'-GCTGTTTCTCCCGAATAGGAACAGG-3'; U8-Lp-24, 5'-GCTGTTTCTCCCAGTGAGGAACAGG-3'; U8-Lp3M, 5'-GGACCGGAGGACAGAGCTTAGTCTTACTCAGTCTCCTCC-3'; U8-Lp4M， 5'-GCCTGGTAAGACAACAGGCACCAGAC-3'; U8-C Boxup, 5'-GCGACTCAGTCTCCTCCATTCATCAATAGGATTTTCTCCCGGAGGAGG3'; U8-Cup-NC, 5'-CCTCCATTCATCATGTACTATGTCTCCCGGAG-3'; U8-Cup-conM, 5'-CCTCCATTCATCATGTTAGCATACTCCCGGAG-3'; U8-C BoxM， 5'-GCGACTCAGTCTCCTCGGACGTAAGTTGTGCTGTTTCTCCCGGAGGAGG 3'; U8-D BoxM, 5'-CCCCGGGTTCGAAAGTCTTAGATCCTGCC- $3^{\prime}$. Mutants were generated by site-directed mutagenesis (Kunkel et al. 1987) using the E. coli strain CJ236 (dut ${ }^{-}$ung $^{-}$) or via PCR (Peculis and Steitz 1993) (for St $1 \mathrm{mu}$ tants).

\section{Oocyte injections}

Oocytes for injection were isolated, prepared, injected, and treated essentially as described (Peculis and Steitz 1993). RNA isolations and analysis of in vivo-labeled RNAs were performed as described (Peculis and Steitz 1993). Enucleated oocytes were prepared according to Ford and Gurdon (1977). Isolated nuclei were prepared as described by Lund and Paine (1990). U8-depleted oocytes were generated as described (Peculis and Steitz 1993), receiving a single injection of deoxyoligonucleotide U8 39-48. U8 RNA was synthesized in vitro in the presence of G-cap or A-cap dinucleotides (Pharmacia) and $\left[\alpha^{-32} \mathrm{P}\right] \mathrm{UTP}$ and $\left[\alpha-{ }^{32}\right.$ P]ATP. After transcription, RNAs were purified by phenol extraction, spun on a G-50 column (Sigma), and precipitated with ethanol. RNAs were dissolved in distilled water at a concentration of $15 \mathrm{ng} / \mu \mathrm{l}$, as determined by specific activity. For the titration rescue experiment, wild-type G-cap RNA was diluted to $7.5 \mathrm{ng} / \mu \mathrm{l}(1 / 2 \times), 3.75 \mathrm{ng} / \mu \mathrm{l}(1 / 4 \times)$ and $1.5 \mathrm{ng} / \mu \mathrm{l}(1 / 10 \times)$. Cytoplasmic injections (enucleated oocytes and whole oocytes) were at a volume of $50 \mathrm{nl} /$ oocyte. Injections into isolated nuclei were $14 \mathrm{nl} /$ nucleus. Oocytes were typically incubated for $14 \mathrm{hr}$ after the last injection prior to analysis. For import studies and anti-fibrillarin precipitations (Fig. 4, A and C, respectively) oocytes were incubated for $6 \mathrm{hr}$ prior to analysis. Isolated nuclei were injected then incubated for $4 \mathrm{hr}$ before assaying. AntiTMG precipitations were performed on RNAs isolated from eight enucleated oocytes $4 \mathrm{hr}$ after injection. For examination of in vivo-labeled RNA, nuclei or the corresponding cytoplasmic compartments were collected and total RNA isolated (Peculis and Steitz 1993). Four oocyte (or nuclear) equivalents were loaded per lane and resolved on $1 \%$ agarose-formaldehyde gels or $8 \%$ denaturing polyacrylamide gels.

\section{S1 nuclease protection assays}

Four hours after microinjection of U8 39-48 deoxyoligonucleotide, the U8-depleted oocytes were injected with G-cap U8 RNA, incubated another $3 \mathrm{hr}$, and injected with $40 \mathrm{nl}$ of $\left.{ }^{32} \mathrm{P}\right] \mathrm{UTP}$ at $5 \mu \mathrm{Ci} / \mu \mathrm{l}$. After a 14 -hr incubation at $18^{\circ} \mathrm{C}$, nuclei were hand isolated and total RNA extracted. The in vivo-labeled RNAs were ethanol precipitated along with unlabeled S1 probe, resuspended in S1 nuclease hybridization buffer (Maniatis et al. 1982), and incubated at $80^{\circ} \mathrm{C}$ for $15 \mathrm{~min}$, then at $60^{\circ} \mathrm{C}$ for $3 \mathrm{hr}$. S1 nuclease (300 units; Pharmacia) was added with the reaction buffer and incubated for $1 \mathrm{hr}$ at $37^{\circ} \mathrm{C}$. Products were resolved on a $5 \%$ polyacrylamide gel. The $\mathrm{S} 1$ probe consisted of the $2.7-\mathrm{kb}$ EcoRI-PstI fragment from pXlr12 plasmid (Dawid and Wellauer 1976). 


\section{Acknowledgments}

We thank Todd Pihl, Vic Myer, Susan Baserga, Liz Scharl, Cathy Joyce, and other members of the Steitz laboratory for helpful discussions and suggestions, and Todd Pihl, Susan Baserga, and Liz Scharl for critical reading of the manuscript. This work was supported in part by grants from the National Institutes of Health, GM14529 to B.A.P. and GM 26154 to J.A.S.

The publication costs of this article were defrayed in part by payment of page charges. This article must therefore be hereby marked "advertisement" in accordance with 18 USC section 1734 solely to indicate this fact.

\section{References}

Amiri, K.A. 1994. Fibrillarin-like proteins occur in the domain Archaea. I. Bacteriol. 176: 2124-2127.

Ares, M. and A.H. Igel. 1990. Lethal and temperature sensitive mutations and their suppressors identify an essential structural element in U2 small nuclear RNA. Genes \& Dev. 4: 2132-2145.

Baserga, S.A. and J.A. Steitz. 1993. The diverse world of small ribonucleoproteins. In RNA world /ed. R.F. Gesteland and J.F. Atkins), pp. 359-382. Cold Spring Harbor Laboratory Press, Cold Spring Harbor, New York.

Baserga, S.J., X.W. Yang, and J.A. Steitz. 1991. An intact Box C sequence in the U3 snRNA is required for binding of fibrillarin, the protein common to the major family of nucleolar snRNPs. EMBO $/$. 10: 2645-2651.

Baserga, S.J., M. Gilmore-Hebert, and X.W. Yang. 1992. Distinct molecular signals for nuclear import of the nucleolar snRNA, U3. Genes \& Dev. 6: 1120-1130.

Bram, R.J., R.A. Young, and J.A. Steitz. 1980. The ribonuclease III site flanking $23 \mathrm{~S}$ sequences in the $30 \mathrm{~S}$ ribosomal precursor RNA of E. coli. Cell 19: 393-401.

Brosius, J., T.J. Dull, and H.F. Noller. 1979. Complete nucleotide sequence of a $23 \mathrm{~S}$ ribosomal RNA gene from Escherichia coli. Proc. Natl. Acad. Sci. 77: 201-204.

Caizergues-Ferrer, M., C. Mathieu, P. Mariottini, F. Amalric, and F. Amaldi. 1991. Developmental expression of fibrillarin and U3 snRNA in Xenopus laevis. Development 112: 317326.

Cecconi, F., P. Mariottini, F. Loreni, P. Pierandrei-Amaldi, N. Campioni, and F. Amaldi. 1994. U17 $7^{\mathrm{xs}}$, a small nucleolar RNA with a 12 nt complementary to $18 \mathrm{~S}$ rRNA and coded by a sequence repeated in the six introns of Xenopus laevis ribosomal protein S8 gene. Nucleic Acids Res. 22: 732-741.

Dahlberg, J.E. and E. Lund. 1988. The genes and transcription of the major small nuclear RNAs. In Small nuclear ribonucleoprotein particles (ed. M.L. Birnstiel), pp. 38-70. SpringerVerlag, New York.

Dawid, I.B. and P.K. Wellauer. 1976. A reinvestigation of $5^{\prime} \rightarrow 3^{\prime}$ polarity in 40S ribosomal RNA precursor of Xenopus laevis. Cell 8: 443-448.

DeRobertis, E.M., S. Lienhard, and R.F. Parisot. 1982. Intracellular transport of microinjected $5 \mathrm{~S}$ and small nuclear RNAs. Nature 295: 572-577.

Finley, D., B. Bartel, and A. Varshavsky. 1989. The tails of ubiquitin precursors are ribosomal proteins whose fusion to ubiquitin facilitates ribosome biogenesis. Nature 338: 394 401.

Fischer, U. and R. Lührmann. 1990. An essential signaling role for the $m_{3} G$ cap in the transport of $U 1$ snRNP to the nucleus. Science 249: 786-790.

Fischer, U., E. Darzynkiewicz, S.M. Tahara, N.A. Dathan, R. Lührmann, and I.W. Mattaj. 1991. Diversity in the signals required for nuclear accumulation of $U$ snRNPs and variety in the pathways of nuclear transport. $J$. Cell Biol. 113: 705714.

Fischer, U., V. Sumpter, M. Sekine, T. Satoh, and R. Lührmann. 1993. Nucleocytoplasmic transport of U snRNPs: Definition of a nuclear localization signal in the Sm core domain that binds a transport receptor independently of the $\mathrm{m}_{3} \mathrm{G}$ cap. EMBO I. 12: 573-583.

Ford, C.C. and J.B. Gurdon. 1977. A method for enucleating oocytes of Xenopus laevis. I. Embryol. Exp. Morphol. 37: 203-209.

Fragapane, P., S. Prislei, A. Michienzi, E. Caffareli, and I. Bozzoni. 1993. A novel small nucleolar RNA (U16) is encoded inside a ribosomal protein intron and originates by processing of the pre-mRNA. EMBO 1. 12: 2921-2928.

Girard, J.-P., H. Lehtonen, M. Caizergues-Ferrer, F. Amalric, D. Tollervey, and B. Lapeyre. 1992. GARI is an essential small nucleolar RNP protein required for pre-rRNA processing in yeast. $E M B O$ I. 11: 673-782.

Hamm, J. and I.W. Mattaj. 1989. An abundant U6 snRNP found in germ cells and embryos of Xenopus laevis. EMBO $\mathrm{F}$. 8: $4179-4187$.

Hamm, J., V.L. vanSanten, R.A. Spritz, and I.W. Mattaj. 1988. Loop I of Ul small nuclear RNA is the only essential RNA sequence for binding of specific U1 small nuclear ribonucleoprotein particle proteins. Mol. Cell. Biol. 8: 4787-4791.

Hamm, J., N.A. Dathan, and I.W. Mattaj. 1989. Functional analysis of mutant Xenopus U2 snRNAs. Cell 59: 159-169.

Hamm, I., E. Darzynkiewicz, S.M. Tahara, and I.W. Mattaj. 1990a. The trimethylguanosine cap structure of U1 snRNA is a component of a bipartite nuclear targeting signal. Cell 62: $569-577$.

Hamm, J., N.A. Dathan, and I.W. Mattaj. 1990b. Multiple domains of U1 snRNA, including U1 specific protein binding sites, are required for splicing. EMBO J. 9: 1237-1244.

Hughes, I.M.X. and M. Ares Jr. 1991. Depletion of U3 small nucleolar RNA inhibits cleavage in the $5^{\prime}$ external transcribed spacer of yeast pre-ribosomal RNA and impairs formation of 18 S ribosomal RNA. EMBO I. 10: 4231-4239.

Jansen, R.P., E.C. Hurt, H. Kern, H. Lehtonen, M. Carmo-Fonesca, B. Lapeyre, and D. Tollervey. 1991. Evolutionary conservation of the human nucleolar protein fibrillarin and its functional expression in yeast. J. Cell Biol. 113: 715-729.

Jarmolowski, A. and I.W. Mattaj. 1993. The determinants for Sm protein binding to Xenopus U1 and U5 snRNAs are complex and non-identical. EMBO I. 12: 223-232.

Jarmolowski, A., J. Zagorski, H.V. Li, and M.J. Fournier. 1990. Identification of essential elements in U14 RNA of Saccharomyces cerevisiae. Mol. Cell. Biol. 9: 4503-4509.

Kambach, C. and I.W. Mattaj. 1992. Intracellular distribution of the U1A protein depends on active transport and nuclear binding to Ul snRNA. J. Cell Biol. 118: 11-21.

Kass, S., K. Tyc, J.A. Steitz, and B. Sollner-Webb. 1990. The U3 small nucleolar ribonucleoprotein functions in the first step of preribosomal RNA processing. Cell 60: 897-908.

Kato, N. and F. Harada. 1984. Nucleotide sequence of nuclear 5.4S RNA of mouse. Biochim. Biophys. Acta 782: 127-131.

Kiss, T. and W. Filipowicz. 1993. Small nucleolar RNAs encoded by introns of the human cell cycle regulatory gene RCC1. EMBO I. 12: 2913-2920.

Krainer, A.R. 1988. Pre-mRNA splicing by complementation with purified human U1, U2, U4/U6 and U5 snRNPs. Nucleic Acids Res. 16: 9415-9429.

Kunkel, T.A., J.D. Roberts, and R.A. Zakour. 1987. Rapid and specific site-directed mutagenesis without phenotypic expression. Methods Enzymol. 154: 367-382. 
Labhart, P. and R.H. Reeder. 1986. Characterization of three sites of RNA $3^{\prime}$ end formation in the Xenopus ribosomal gene spacer. Cell 45: 431-443.

Li, H.V., J. Zagorski, and M.J. Fournier. 1990. Depletion of U14 small nuclear RNA ( $\operatorname{snR} 128$ ) disrupts production of $18 \mathrm{~S}$ rRNA in Saccharomyces cerevisiae. Mol. Cell. Biol. 10: 1145-1152.

Lischwe, M.A., R.L. Ochs, R. Reddy, R.G. Cook, L.C. Yeoman, E.M. Tan, M. Reichlin, and H. Busch. 1985. Purification and partial purification of a nucleolar scleroderma antigen $(\mathrm{Mr}=34,000 ; \mathrm{pI}, 8.5)$ rich in $\mathrm{N}^{\mathrm{G}}-\mathrm{N}^{\mathrm{G}}$-dimethylarginine. $/$. Biol. Chem. 260: 14304-14310.

Liu, J. and E.S. Maxwell. 1990. Mouse U14 is encoded in an intron of the mouse cognate hsc 70 heat shock gene. Nucleic Acids Res. 18: 6565-6571.

Lund, E. and P.L. Paine. 1990. Non-aqueous isolation of transcriptionally active nuclei from Xenopus oocytes. Methods Enzymol. 181: 36-41.

Maniatis, T., E.F. Fritsch, and J. Sambrook. 1982. Molecular cloning: A laboratory manual. Cold Spring Harbor Laboratory, Cold Spring Harbor, New York.

Marshallsay, C. and R. Lührmann. 1994. In vitro nuclear import of snRNPs: Cytosolic factors mediate $\mathrm{m}_{3} \mathrm{G}$-cap dependence of U1 and U2 snRNP transport. EMBO $J$. 13: 222-231.

Mattaj, I.W. 1986. Cap trimethylation of U snRNA is cytoplasmic and dependent on $U$ snRNP protein binding. Cell 46: $905-911$.

1988. U snRNP assembly and transport. In Small nuclear ribonucleoprotein particles (ed. M.L. Birnstiel), pp. 100-114. Springer-Verlag, New York.

McPheeters, D.S. and J. Abelson. 1992. Mutational analysis of the yeast U2 snRNA suggests a structural similarity to the catalytic core of group I introns. Cell 71: 819--831.

Moore, M.)., C.C. Query, and P.A. Sharp. 1993. Splicing of precursors to mRNAs by the spliceosome. In RNA world (ed R.F. Gesteland and J.F. Atkins), pp. 303-357. Cold Spring Harbor Laboratory Press, Cold Spring Harbor, New York.

Morrissey, J.P. and D. Tollervey. 1993. Yeast snR30 is a small nucleolar RNA required for $18 \mathrm{~S}$ rRNA synthesis. Mol. Cell. Biol. 13: 2469-2477.

Pan, Z.Q. and C. Prives. 1989. U2 snRNA sequences that bind U2-specific proteins are dispensable for the function of U2 snRNP in splicing. Genes \& Dev. 3: 1887-1898.

Peculis, B.A. and J.A. Steitz. 1993. Disnuption of U8 nucleolar snRNA inhibits $5.8 \mathrm{~S}$ and $28 \mathrm{~S}$ rRNAprocessing in the Xenopus oocyte. Cell 73: 1233-1245.

Prislei, S., A. Michienzi, C. Presutti, P. Fragapane, and I. Bozzoni. 1993. Two different snoRNAs are encoded in introns of amphibian and human Ll ribosomal protein genes. Nucleic Acids Res. 21: 5824-5830.

Raué, H.A. and R.J. Planta. 1991. Ribosome biogenesis in yeast. Prog. Nucleic Acid Res. Mol. Biol. 41: 89-129.

Reddy, R., D. Henning, and H. Busch. 1979. Nucleotide sequence of nucleolar U3B RNA. J. Biol. Chem. 254: 1109711105.

- 1985. Primary and secondary structure of U8 small nuclear RNA. J. Biol. Chem. 260: 10930-10935.

Reimer, G., K.M. Pollard, C.A. Penning, R.L. Ochs, M.A. Lischew, and E.M. Tan. 1987. Monoclonal antibody from (New Zealand Black $\times$ New Zealand White) $F$ l mouse and some human scleroderma sera target a $\mathrm{M}_{\mathrm{r}} 34,000$ nucleolar protein of the U3-ribonucleoprotein particle. Arthritis Rheum. 30: $793-800$.

Ruff, E.A., O.J. Rimoldi, B. Raghu, and G.L. Eliceiri. 1993. Three small nucleolar RNAs of unique nucleotide sequences. Proc. Natl. Acad. Sci. 90: 635-638.
Savino, R. and S.A. Gerbi. 1990. In vivo disruption of Xenopus U3 snRNA affects ribosomal RNA processing. EMBO $J$. 9: 2299-2308.

Schimmang, T., D. Tollervey, H. Kern, R. Frank, and E.C. Hurt. 1989. A yeast nucleolar protein related to mammalian fibrillarin is associated with small nucleolar RNA and is essential for viability. $E M B O$ /. 8: 4015-4024.

Stroke, I.L. and A.M. Weiner. 1989. The $5^{\prime}$ end of U3 snRNA can be cross-linked in vivo to the external transcribed spacer of rat ribosomal RNA precursors. I. Mol. Biol. 210: 497-512.

Terns, M.P. and J.E. Dahlberg. 1994. Retention and 5' cap trimethylation of U3 RNA in the nucleus. Science 264: 959961.

Tollervey, D., H. Lehtonen, M. Carmo-Fonesca, and E.C. Hurt. 1991. The small nucleolar RNP protein NOPl (fibrillarin) is required for pre-rRNA processing in yeast. EMBO $J$. 10: $573-$ 583.

Tyc, K. and J.A. Steitz. 1989. U3, U8 and U13 comprise a new class of mammalian snRNPs localized in the cell nucleolus. EMBO I. 8: 3113-3119.

- 1992. A new interaction between the mouse 5 ' external transcribed spacer of pre-rRNA and U3 snRNA detected by psoralen crosslinking. Nucleic Acids Res. 20: 5375-5382.

Tycowski, K., M.-D. Shu, and J.A. Steitz. 1993. A small nucleolar RNA is processed from an intron of the human gene encoding ribosomal protein S3. Genes \& Dev. 7: 1176-1190

van Nues, R.W., J. Venema, R.J. Planta, and H.A. Raué. 1993. Ribosomal RNA processing in Saccharomyces cerevisiae. In The translational apparatus (ed. K.H. Niestieus, A.R. Subramanian, V.A. Erdmann, F. Franceschi, and B. WittmannLiebold), pp. 151-162. Plenum Press, New York.

Vankan, P., C. McGuigan, and I.W. Mattaj. 1990. Domains of $\mathrm{U} 4$ and U6 snRNAs are required for snRNP assembly and splicing complementation in Xenopus oocytes. EMBO $/$. 9: 3397-3404.

Veldman, G.M., J. Klootwijk, H. von Heerikhuizen, and R.J. Planta. 1981. The nucleotide sequence of the intergenic region between the $5.8 \mathrm{~S}$ and $26 \mathrm{~S}$ rRNA genes of the yeast rRNA operon. Possible implications for the interraction between 5.8S and 26S rRNA and the processing of the primary transcript. Nucleic Acids Res. 9: 4847-4862.

Wells, S.E. and M. Ares. 1994. Interactions between highly conserved U2 snRNA structures and PRP5, PRP9, PRP11, and PRP21 proteins are required to ensure integrity of the U2 snRNP in yeast. Mol. Cell. Biol. 14: 6337-6349.

Young, R.A. and J.A. Steitz. 1978. Complementary sequences 1700 nucleotides apart form a RNase III cleavage site in $E$. coli ribosomal precursor RNA. Proc. Natl. Acad. Sci. 75: 3593-3597.

Zavanelli, M.I. and M. Ares Jr. 1991. Efficient association of U2 snRNPs with pre-mRNA requires and essential U2 RNA structural element. Genes \& Dev. 5: 2512-2533. 


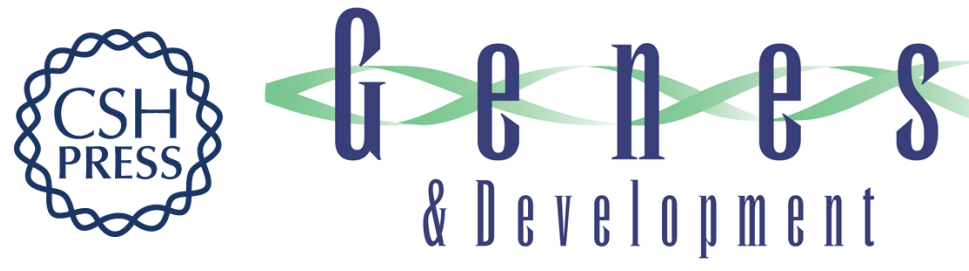

\section{Sequence and structural elements critical for U8 snRNP function in Xenopus oocytes are evolutionarily conserved.}

B A Peculis and J A Steitz

Genes Dev. 1994, 8:

Access the most recent version at doi:10.1101/gad.8.18.2241

References This article cites 62 articles, 20 of which can be accessed free at:

http://genesdev.cshlp.org/content/8/18/2241.full.html\#ref-list-1

License

Email Alerting

Service

Receive free email alerts when new articles cite this article - sign up in the box at the top right corner of the article or click here.

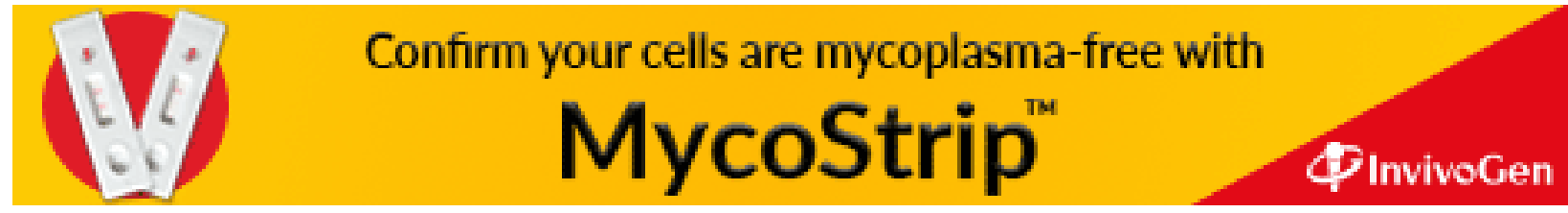

